Full length article

\title{
Do notional defined contribution schemes prolong working life? Evidence from the 1994 Swedish pension reform
}

\author{
Haodong Qi ${ }^{\mathrm{a}, \mathrm{b}, *}$, Jonas Helgertz ${ }^{\mathrm{b}}$, Tommy Bengtsson ${ }^{\mathrm{b}, \mathrm{c}, \mathrm{d}}$ \\ ${ }^{a}$ Demography Unit, Department of Sociology, Stockholm University, Sweden \\ ${ }^{\mathrm{b}}$ Centre for Economic Demography and Department of Economic History, Lund University, Sweden \\ ' IZA, Germany \\ ${ }^{\mathrm{d}}$ Centre for Economic Policy Research (CEPR), London, United Kingdom
}

\section{A R T I C L E I N F O}

\section{Article history:}

Available online $\mathrm{xxxx}$

\section{JEL classification:}

H55

$\mathrm{J} 18$

J26

\section{Keyword:}

Education, Occupation

Pension

Reform

Retirement

\begin{abstract}
A B S T R A C T
This paper investigates whether the Notional Defined Contribution (NDC) scheme prolongs working life. The evidence from the 1994 Swedish pension reform shows a gender and socio-economic gradient in the labor supply responses to phasing in NDC. While the reform exerted a large and significant positive effect on the average retirement age among highly educated and skilled, it had little or negative effect on those with low level of human capital. And the overall effect is more profound among older men, compared to older women. These findings imply that the aggregate impact of NDC may only be positive if the average level of older workers' education and skills is high, whereas it may be moderate (or even adverse) if the majority of the older workers are less educated and engage in low-skill jobs. This highlights the importance of incorporating the gender and socio-economic aspects into the evaluation of how a multi-pillar pension scheme, such as NDC, may increase the average working life expectancy.
\end{abstract}

(C) 2016 Elsevier B.V. All rights reserved.

\section{Introduction}

Notional Defined Contribution (NDC) pension scheme links workers' pension contribution more closely to their retirement benefits, compared to the defined-benefit pay-as-you-go system, which implies that the more years they work, the more pension income they will entitle to. While, technically, NDC may create strong incentives for postponing retirement, empirical evidence regarding the extent to which, the NDC scheme may prolong working life has been rare for two reasons. First, the number of countries having implemented such a system are handful, merely four countries reformed the pension systems by phasing in NDC scheme during the 1990s, which are Sweden, Italy, Latvia, and Poland (Holzmann and Palmer, 2006). Second, the labor supply effect was impossible to be examined previously, as population who were effectively affected by the NDC had not yet approached their pensionable age. Recently, some of the birth cohorts who were effectively affected by the Swedish NDC system have reached their late 60s, which, therefore, provides an opportunity to empirically examine whether NDC pension scheme may prolong working life.

* Corresponding author at: Demography Unit, Department of Sociology, Stockholm University, SE-106 91 Stockholm, Sweden.

E-mail address: haodong.qi@sociology.su.se (H. Qi).
Previous studies mostly documented positive effects of changes to pension and retirement policy on older workers labor supply. Laun and Wallenius (2015) predicted an overall increase of 2.5 years in the average retirement age in response to the 1994 pension reform in Sweden. Laitner and Silverman (2012) simulated a payroll tax cut after age 54 for the US and concluded that such a reform would increase retirement age by one year or more. Recent trend increases in the effective retirement age across many OECD countries (increased from 63.2 to 64.6 for men and from 61.1 to 63.2 for women between 1998 and 2014 across the 34 members of $\mathrm{OECD}^{1}$ ) are widely believed as consequences of governments' interventions, to raise statutory retirement ages, restrict early retirement schemes, and/or impose benefit reduction for early withdrawal from the labor force (Buchholz et al., 2013; Chan and Stevens, 2004; Glans, 2008; Hakola and Uusitalo, 2005; Karlström et al., 2008; Komp et al., 2010; Staubli and Zweimuller, 2013). While pension reform oftentimes treats all workers in a uniform way, its impact may differ depending on individual characteristics. The aforementioned studies mostly found positive labor supply effect of pension policy change at the aggregate level. Whether this effect holds for individuals with different characteristics remains unclear. This paper

\footnotetext{
${ }^{1}$ OECD statistics on the average effective age of retirement in 1970-2014 in OECD countries: http://www.oecd.org/els/emp/average-effective-age-of-retirement.htm.
} 
examines how the NDC pension scheme affect individuals across different socio-economic groups.

Our ambition to investigate the individual-level responses to a macro policy amendment was made possible by exploiting a large population database with rich individual-level information, the Swedish Inter-disciplinary Panel (SIP). This longitudinal dataset covers the entire population residing in Sweden sometime between 1968 and 2011, including yearly income from all sources, as well as a broad set of socio-economic and demographic variables. The population-wide coverage data makes our study distinguishable from many prominent empirical works. For example, Berkovec and Stern (1991), Lumsdaine et al. (1992), Ruhm (1996), and Stock and Wise (1990) all relied on small-sample data, which prevented them from examining the retirement behavior of older women, due to small number of female workers remained in the labor force at older age. Our data, however, contains a large number of women working at older age, which provides an opportunity to investigate older women's responses to the pension reform in a detailed manner, particularly among those who are less educated, a group which until now has received very limited attention in the literature.

While Qi et al. (2016) and Qi (2016) recently found that retirement age increases across those born between 1938 and 1944 who were effectively affected by the Swedish NDC, regardless of gender, education, and health, the present study finds that the underlying mechanisms driving these changes appear to have been different across these different groups. The NDC scheme phased in during the 1994 Swedish pension reform plays a key role in explaining the postponed retirement for men, whereas it contributes little to the increase in women's average retirement age, a gender distinction that has not been uncovered previously. Furthermore, the labor supply effects of NDC are large and positive among olderworkers with high level of education and skills, whereas they are negligible or even adverse among those less educated and skilled.

These gender and socio-economic differences in responses to the retirement policy change are of great importance for pension reformers to consider when assessing the cost and benefit of phasing in the NDC system. The extent to which NDC may increase the population average working life expectancy may be a function of the educational and occupational composition of the old-aged labor force. If the labor force contains a decent share of highly educated and skilled older workers, a positive impact may be expected. Conversely, if the majority of old-aged labor force having attained low level of education and skills, the expected effect at the population level might be small, or even adverse. Our findings also cast doubt on the argument that retirement policy change may effectively increase average retirement ages (Laun and Wallenius, 2015; Laitner and Silverman, 2012). Their simulation-based assessment of the reform effects might be misleading if the responses to policy change are not differentiated by gender and socio-economic status. These dimensions, as suggested by our empirical evidence, should be central to evaluate the effectiveness of retirement policies, namely how long NDC may prolong working life.

The organization of this paper is as follows. Section 2 gives a brief account of the Swedish pension system, and the major reforms implemented during the 1990s. Section 3 describes our basic retirement model. Section 4 discusses our data, sample selection, and empirical strategy to identify the reform effects. Section 5 presents the empirical results. Section 6 concludes.

\section{The great reform in the Swedish pension system}

Sweden followed a long-term trend towards early retirement until the late-1990s. Some argue that this trend is attributable to the generosity of disability insurance (DI) since the early 1970s.
Over the period 1970-1991, workers aged $60+$ could retire through DI with labor market reasons, such as unemployment, which largely explains the declining labor force participation among the older workers during the period (Hagen, 2013). During the 1990s, the Swedish government implemented two major reforms concerning DI; first by abolishing the utilization of DI for labor market reasons in 1991, and secondly, by eliminating the favorable rules for workers aged 60-64 in 1997.

The labor supply effects of these DI reforms have been studied by Karlström et al. (2008), who found a positive impact on the labor force participation rate. Moreover, this study also showed large anticipation effects of the reform, due to the fact that the reform was announced two years prior to its implementation. As a result, the transition from unemployment to DI almost doubled, corresponding to about $2 \%$ of the labor force between ages 60 and 64 , during the year before the reform was implemented. Karlström et al. (2008) argued those who transitioned were mainly the DI applicants aged 60-64 in 1996 (born 1932-1936), who believed that they would be eligible for DI under the pre-reform regime, but not under the post-reform regulation. Furthermore, according to Karlström et al. (2008), the application had to be filed before January 1,1997 , meaning the last group who benefited from the favorable rule of DI were those aged 60 on December 31, 1996, the 1936 cohort.

However, the period of investigation in Karlström et al. (2008) ended in 2001, thus further developments in old-age labor supply remain unclear. Some have shown that the average exit age from labor market increased approximately one month per year between 2000 and 2011 (Karlsson and Olsson, 2012). Was such an increase a response to the changes in stringency of DI admission? This question is difficult to answer because the post-DI reform period overlapped with the old-age pension reform which was proposed in 1994, implemented in 1999, and started paying out benefits in 2001 (Hagen, 2013).

The reformed old-age pension system comprises three main pillars: the universal covered guarantee part, Notional Defined PayAs-You-Go, and privately managed fully funded accounts (Palmer, 2000; Hagen, 2013). For the income related PAYG pillar, there was a gradual transition from the old Allmän Tilläggspension (ATP) system to NDC, which was implemented over 16 years. The first recipient of NDC were those born in 1938, whereby one-fifth of their pension was calculated based on the NDC rule, and the remaining four-fifths based on the old ATP rule. The NDC part, as a share of the total income related benefit from the public oldage pension, increased by 5 percentage points for each successive cohort up to those born in 1953. Hence, the pension entitlements for those born in 1954 or later are accounted by a complete conversion of the accumulated pension credits from the old ATP system into the new NDC system (Palmer, 2000; Settergren, 2001; Konberg et al., 2006; Hagen, 2013). All benefits will be completely paid from the NDC system by the year 2040 (Sunden, 2006.).

The ATP and NDC pension schemes are different in many aspects. The former has a defined benefit feature which has been proven to be unsustainable given the context of demographic ageing, whereas the latter is in the defined contribution spirit, which has the potential for ensuring long-term sustainability. From the individual's perspective, the two systems can be mainly distinguished by two features, the importance of earning history and the divisor for calculating pension benefits. These two factors create the differences between ATP and NDC as they lead to differences in the rate of return.

Under the ATP, only the best 15 years of earnings during the working life are used to calculate one's pension entitlements, whereas, under the NDC, the entire life earnings are taken into account for calculating benefits. This fundamental difference between the two schemes creates stronger incentives for workers 
to postpone retirement under the NDC system. This is because under the best-15-year rule, workers would not expect any increase in their final pension benefits as the highest earning over the life cycle tends to occur before age 50 (Laun and Wallenius, 2015). However, NDC implies that the entirety of pre-retirement labor income will be relevant for calculating entitlements, thus additional years of earnings at old ages will increase expected benefits. It is also noteworthy that the best-15-year rule in ATP generates significant redistribution from low- to high-income earners and from women to men, simply because the peak of the labor income over the life cycle is typically higher for men and highincome earners. This potentially treats workers with equivalent lifetime earnings, but with inequivalent life-cycle earning profiles, unequally (Laun and Wallenius, 2015). Therefore, NDC addresses this equity issue inherent to ATP by taking full life time earnings into account.

The second important feature that distinguishes NDC from ATP is the divisor to calculate the annuity. The divisor is a function of remaining life expectancy, which is determined by age and cohort, and not by gender and previous earning history. This divisor, however, implies benefit reduction for those participating in the NDC system (i.e. for those born in 1938 or later). As long as life expectancy continues to increase, the younger generation will receive ever decreasing monthly pension benefits, since the divisor is an increasing function of remaining years of living (Hagen, 2013). Such a mechanism also creates incentives for delaying retirement, because an additional year of working not only gives a one more year contribution to the pension assets, but it also deducts one year of remaining life expectancy from the divisor. This is particularly important for retirement income between ages 60 and 64, since from age 65 workers will be able to claim a guaranteed pension which can potentially top up the monthly pension benefits. Hence, as some have pointed out, the lifetime pension income as a function of retirement age is very flat in ATP, whereas it increases steeply under NDC (Laun and Wallenius, 2015; Palmer, 2000). The effect of retiring at age 66 will be an increase in monthly pensions of about 9 percent, and the effect of retiring at age 67 will result in a nearly 20 percent increase, compared to retiring at age 65 (Konberg et al., 2006).

Having briefly summarized the historical reforms of the DI and old-age pension system, our first conclusion is that to identify the labor supply effects of DI reform and/or the 1994 pension reform is challenging, as these reforms took place simultaneously. To eliminate the effect of DI reform, we condition our sample on those born from 1937 onward, because the 1937 cohort are identical to all later born in terms of facing the same stringency of the DI eligibility rule. However, they differ from those born in 1938 or later since their old-age pension benefits were completely calculated by ATP rules. Therefore, the remainder of the paper will examine the difference in retirement between the 1937 cohort who were unaffected by the 1994 pension reform, and those born in 1938 or later who were affected.

\section{A simple retirement model}

We assume that the time horizon for each individual to choose between work and retirement starts from age 60 . This is because income-related pension benefits are payable from age 60 onwards in the ATP system, and from age 61 onwards in the NDC system. Moreover, the last year of possible employment is assumed to be age 67. This is motivated by the fact that the 2001 Employment Act allows workers to be fully engaged in labor activity up to and including age 67.

Our retirement model is a simplified version of a dynamic programming model. The main assumption we impose is the zero dis- counting factor. The reason for such simplification is that our analysis is based on the entire population, and the challenge of recursive computation in dynamic programming using such a large sample would be too burdensome. One might argue that this is a strong assumption, as it eliminates forward looking behavior. However, previous empirical evidence has shown that there is no difference in the estimated coefficient signs between the static and dynamic models, only in coefficient sizes. For example, the coefficient estimates in Berkovec and Stern (1991) differed only in magnitudes, and not in signs, across the model with 0 and 0.95 discounting factors. Moreover, empirical evidence in Qi (2015) showed that the inter-temporal substitution behavior was largely outweighed by the intra-temporal substitution behavior among older workers (aged 60 $+)$ in Sweden. Such evidence implies that the static assumption in the simplified retirement model might not be so strong, as older workers might become myopic once approaching the end of the life-cycle. Hence, we model individuals' work history as a static choice problem between work and retirement over a discrete and finite time horizon between ages 60 and 67 .

\section{Values of working and retirement}

The choices of work and retirement are modeled in a random utility set up, which conventionally comprises two components, the observed part of the utility and the remaining unobserved proportion of the utility. Hence, in the context of deciding whether to continue working or to retire, the utility of the two choices may be expressed by the following two equations, respectively:

$U_{W}=V_{W}+\epsilon_{W}$

$U_{R}=V_{R}+\epsilon_{R}$

where, $V$ denotes the observed utility, and $\epsilon$ is the unobserved part. Subscripts $W$ and $R$ refer to the choices of working and retiring.

We define the observed utility, $V$ in (1) and (2), as:

$V_{W}=V_{W}(Y)+V_{W}(X)$

$V_{R}=V_{R}(B)+V_{R}(X)$

where, $Y$ and $B$ are labor and pension income, respectively. $X$ is a set of exogenous individual characteristics.

The first term on the right hand side of (3) and (4) corresponds to the pecuniary value of being in the labor force and retirement, respectively, which is solely determined by labor and pension income. The second term of both Eqs. (3) and (4) refers to the non-pecuniary value of being in either state. One might interpret this term as the non-financial utility flow. It is important to note that the variables in the pecuniary value functions in (3) and (4) are alternative-specific, meaning that individuals only derive utility from labor income $Y$ if they remain in the workforce, and from pension $B$ if they are retired. The non-pecuniary value functions has the exogenous variable $X$ that is constant across the choices of working and retire.

\section{Probability of retiring}

The probability of choosing to retire may be simply defined as:

$$
\begin{aligned}
\operatorname{Pr}(R) & =\operatorname{Pr}\left(U_{R}>U_{W}\right) \\
& =\operatorname{Pr}\left(V_{R}+\epsilon_{R}>V_{W}+\epsilon_{W}\right) \\
& =\operatorname{Pr}\left(V_{R}-V_{W}>\epsilon_{W}-\epsilon_{R}\right)
\end{aligned}
$$

From (5), it is clear that the probability of retiring is the cumulative density function (CDF) of $\epsilon_{W}-\epsilon_{R}$ that is below a certain threshold (i.e. the difference between the value of retiring and working $\left(V_{R}-V_{W}\right)$ ). Let $\xi_{V}$ be the value difference $V_{R}-V_{W}$ and 
$\xi_{\epsilon}$ be the difference of two random errors $\epsilon_{W}-\epsilon_{R}$, thus the probability in (5) may be re-written as:

$\operatorname{Pr}(R)=\int I\left(\xi_{V}>\xi_{\epsilon}\right) f\left(\xi_{\epsilon}\right) d \xi_{\epsilon}$

where, $I(*)$ indicates whether the argument, $\xi_{V}>\xi_{\epsilon}$, is true. $f(*)$ is a density function of $\xi_{\epsilon}$.

Since we have discussed the observed part of utility, $V$, the remaining issue to be addressed in order to calculate the probability of retirement is the assumption on the distributions of $\epsilon_{W}, \epsilon_{R}$, as well as $\xi_{\epsilon}$. Because $\epsilon_{W}, \epsilon_{R}$, and $\xi_{\epsilon}$ are unobserved, to compute the probability of retiring requires the integration of $\operatorname{Pr}(R) \mid \xi_{\epsilon}$ over all values of $\xi_{\epsilon}$ weighted by the density function, $f\left(\xi_{\epsilon}\right)$. The integral in (6) may be evaluated either by numerical solution or closed form solution. It is well known that the former method is much more computationally intensive than the latter. Therefore, we choose the closed form solution to proceed with our retirement model.

To derive the closed form solution for computing the probabilities of retiring, three assumptions on $\epsilon_{W}$ and $\epsilon_{R}$ are needed. First, the two errors are independent of each other. Second, both errors are identically distributed. Third, each of the errors follows a Gumbel distribution (Type-I extreme value distribution). The last assumption is motivated by the fact that the difference between the two Gumbel distributed variables follows a logistic distribution. More explicitly, if $\epsilon_{W}$ and $\epsilon_{R}$ are independently and identically distributed extreme values, then $f\left(\xi_{\epsilon}\right)$ is a logistic distribution.

Having imposed the above three assumptions on the $\epsilon$ 's, the probabilities of retiring have closed form corresponding to the logit transformation of the pecuniary and non-pecuniary part of the value functions, as in (9) and (10). Therefore, the probability of retiring can be expressed as:

$\operatorname{Pr}(R)=\frac{\exp \left(V_{R}\right)}{\exp \left(V_{W}\right)+\exp \left(V_{R}\right)}$

\section{Model interpretation}

It is well known that, for discrete choice data, the value of each of the choices can only be identified relative to some reference. In the present context, we are only interested in the difference between the values of being retired and remaining in the labor force. We choose the alternative, working, as the base, and therefore, (7) may be re-written as:

$\operatorname{Pr}(R)=\frac{\exp \left(V_{R}-V_{W}\right)}{1+\exp \left(V_{R}-V_{W}\right)}$

The value functions in (3) and (4) are assumed to be a linear combination of all the covariates and the associated parameters. Therefore, (3) and (4) may be explicitly written as:

$V_{W}=\alpha Y+\gamma_{W} X$

$V_{R}=\beta B+\gamma_{R} X$

From (9) and (10), the value difference between retiring and working is:

$V_{R}-V_{W}=\beta B-\alpha Y+\left(\gamma_{R}-\gamma_{W}\right) X$

The interpretation for the non-pecuniary value is straightforward, since the exogenous individual characteristics in $X$ are constant across choices. Thus the term $\gamma_{R}-\gamma_{W}$ may be interpreted as the value of retiring relative to the value of working for fixed values of $X$.

The $\alpha$ and $\beta$ are essentially the marginal utility of labor income while working and the marginal utility of pension benefits while retired, respectively. Assuming that $B$ and $Y$ gives a constant utility, the ratio of $\beta$ to $\alpha$ can therefore be interpreted as the marginal rate of substitution of pension in terms of labor income. For example, if $\frac{\beta}{\alpha}=2$, an individual would choose to sacrifice two unit of income from labor for each unit of income receivable from pension. In other words, the higher the $\frac{\beta}{\alpha}$ is, the stronger preference for retirement will be.

\section{Data and method}

Our analysis relies on data from the Swedish Interdisciplinary Panel (SIP), which contains ample information on individual labor market outcomes, such as income and occupational attainment, as well as socio-demographic and health characteristics. SIP consists of individual level data from several different administrative registers, including the income and taxation registers, the inpatient register and the total population register (RTB). These multiple registers are merged to create a longitudinal database covering roughly 12 million unique individuals born between 1930 and 1980 who resided in Sweden sometime during the period 19682013. The database allows for studies examining individuals behavior towards the end of their labor market careers, from a life course perspective.

\section{Sample selection}

As we discussed, the DI reform was implemented in 1997. This may have created incentives for early retirement among those who were under the favorable rules of DI. To isolate this potential effect from the old-age pension reform, one needs to ensure the observations in the sample were exposed to identical policy settings, except the old-age pension reform. For this, we extracted data on the cohorts born between 1937 and 1944 from SIP, which includes 342,287 men and 344,506 women. This is because the oldest cohort born in 1937 was no longer under favorable rule of DI, but were under the identical DI policy setting to all the later born cohorts. Furthermore, this cohort was not affected by the old-age pension reform, thus an ideal reference group.

Another sample selection criterion is that all the individuals are not yet retired at age 59 . We use labor and pension income information to define retirement. The labor income comprises wages, salaries, sickness benefits, parental benefits, and unemployment benefits. The pension income includes payments received from old-age pension and disability insurance. A person is defined as retired if the sum of any sorts of pension income exceeds the labor income during the year. This implies that partial retirement is counted as working if the associated retirement income does not exceed income from labor. Furthermore, workers who are unemployed and/or on sick leave are treated as being in the working state, since they are still part of the labor force.

The age pattern of retirement in our sample are depicted in Fig. 1, which compares the probability of remaining in the labor force for the oldest cohort unaffected by the 1994 reform, and for the youngest cohort whose pension benefits were calculated by both ATP and NDC. More specifically, for the youngest cohort born in 1944, half of their total old-age pension income was derived based on the ATP system, and the remaining half was calculated by NDC rules. The difference between the two survival curves in each panel in Fig. 1 suggests that the younger cohort remained in the labor market longer than the older cohort.

Table 1 summarizes the probability of remaining in the labor force at age 67 across all birth cohorts 1937-1944. It is evident that the share of the 67 years old, for both men and women, remained in the labor force increased substantially over these cohorts. For example, $12 \%$ men and 9\% women born in 1944 were still active in the labor market, whereas the corresponding figure for those born in 1937 were merely $4 \%$ and $2 \%$. 


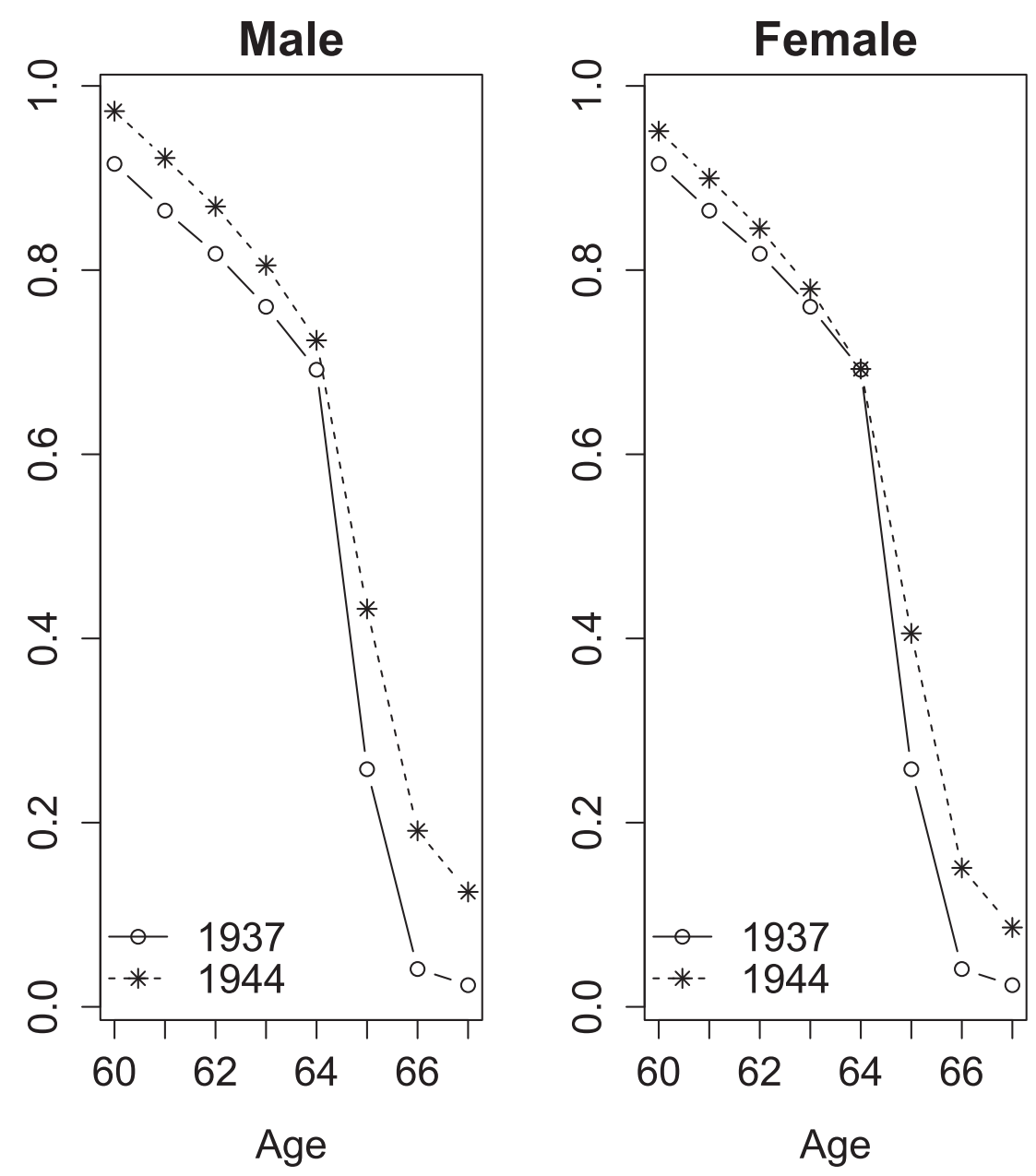

Fig. 1. Age pattern of probability of remaining in the labor force conditioning on working at age 59 .

We followed all individuals from age 60 to 67 , assuming that all workers retire at age 67. This assumption is due to two reasons. First, the 2001 Employment Act allows workers to be fully engaged in labor activity up to and including age 67 . And second, as shown in Table 1, the small proportion remained in the workforce among those older cohorts prevents us from investigating labor force participation beyond age 67 , as once the sample are stratified by education and occupation, very few individuals are observed as workers among those less educated and low skilled.

The final sample comprises 307,958 men and 299,239 women. After having censored the events of retire, emigration, and death, our sample ends up with 1,781,701 person-year for men and $1,661,793$ person-year for women.

\section{Potential labor and pension income}

A typical challenge for estimating a structural retirement model, such as the option value model by Stock and Wise (1990) and dynamic programming model by Berkovec and Stern (1991), is to deal with the unobserved potential income variables. For example, how much pension a worker would have received if he or she choose to retire in a given year. Similarly, how much labor income a worker would have been able to make if he or she remains in the labor force. These potential income variables are needed for estimating the marginal rate of substitution between labor income and pension, i.e. the ratio of $\beta$ to $\alpha$ in (9) and (10). And therefore, to estimate our previously specified retirement model, we need to impute the unobserved income data. The fol-
Table 1

Probability of remaining in the labor force at age 67 by cohorts.

\begin{tabular}{lll}
\hline Cohort & Men & Women \\
\hline 1937 & 0.04 & 0.02 \\
1938 & 0.06 & 0.04 \\
1939 & 0.07 & 0.05 \\
1940 & 0.08 & 0.05 \\
1941 & 0.09 & 0.06 \\
1942 & 0.10 & 0.07 \\
1943 & 0.11 & 0.08 \\
1944 & 0.12 & 0.09 \\
\hline
\end{tabular}

lowing briefly illustrates how we overcome this challenge in our analysis.

Labor income was observed for each individual only up to the age prior to the first year of retirement, as workers are assumed to receive no labor income upon exiting the labor force. Hence, the missing labor income during the first year of retirement was imputed by the labor income received during the year before retirement. There is no need to impute missing labor income after the first year of retirement, as observed individuals are censored after the retirement event occurred.

As we mentioned in the data section, pension income came mainly from two sources, disability pension and old-age pension. We did not impute the disability pension if it is missing, and simply replaced missing values with zero. The old-age pension (OA) was imputed by a pension forecasting equation, which was estimated by regressing the observed old-age pension benefits on a 
number of time-varying and time-constant covariates. The implicit specification of the pension regression may be written as:

$O A_{i, t}=f\left(t, c, Z_{i}, S_{i, t}, \theta\right)$

where, $t$ is age. $c$ is the dummy indicator for each of the birth cohorts. $Z_{i}$ is a set of time-constant covariates: sex, education, and country of origin. $S_{i, t}$ is a set of time-varying covariates: marital status, occupation, and accumulated labor income since age 55 $\left(\sum_{i=55}^{t-1} Y(t)\right) . \theta$ is a vector of parameters.

We used the estimated coefficients and the observed values of all covariates in Eq. (12) to predict the expected pension (i.e. $\left.E\left(O A_{i, t} \mid t, c, Z_{i}, S_{i, t}, \theta\right)\right)$. The counter-factual pension was simulated by imposing the cohort variable equal to 1937 (i.e. $\left.E\left(O A_{i, t} \mid t, c=1937, Z_{i}, S_{i, t}, \theta\right)\right)$. This essentially eliminated the cohort difference in benefit accounting in order to generate a counterfactual scenario that the 1994 pension reform did not take place. The mean values of the predicted and the counter-factual pension are presented in Table 2 . The statistics reveal some notable gender distinction. While men, on average, earn $42 \%$ more than women if they work, their expected pension (predicted by Eq. (12)) is merely $23 \%$ higher. This indicates that the marginal rate of substitution of pension in terms of labor income would be higher for men, simply because they have to give up more unit of labor earnings for each unit of pension income.

By comparing the average expected pension with the counterfactual one, the gender difference in pension before the reform $(23,078$ SEK per year) is twice larger than the post-reform difference $(11,218$ SEK per year). This diminishing gender distinction is mainly due to the gradual phasing in of NDC. As discussed in the previous section, the old ATP system calculates the pension benefits based on the best-15-year rule, given the unequal lifecycle earning profile between men and women, the old system generates significant redistribution from low to high income earners, and typically from women to men. The NDC on the other hand treats workers with equivalent lifetime earnings, but inequivalent life-cycle earning profiles, equally (Laun and Wallenius, 2015). As a result, the redistribution from women to men was mitigated, and the gender difference in pension diminished via the reform.

Table 2 also shows that women are, on average, slightly more educated than men, as the proportion attained university or higher education is $4 \%$ higher. However, this educational advantage do not translate into larger share of high-skill occupation, the share of men with high-skill jobs is $12 \%$ higher than women. Among the low-skill labor, women are mostly working in the service sector, whereas men are more likely to engage in manual jobs.

\section{Retirement probabilities}

The theoretical retirement model derived previously forms the basis for estimating retirement probabilities. The empirical model corresponding to the theoretical model (expressed by (3) and (4)) may be explicitly specified as follows:

$V_{W, i, t}=\alpha Y_{i, t}+\gamma_{W} X_{i, t}$

$V_{R, i, t}=\beta\left[E\left(O A_{i, t} \mid t, c, Z_{i}, S_{i, t}, \theta\right)+D I_{i, t}\right]+\gamma_{R} X_{i, t}$

where, $Y_{i, t}$ is labor income. $E\left(O A_{i, t} \mid t, c, Z_{i}, S_{i, t}, \theta\right)$ is expected old-age pension income predicted by (12). $D I_{i, t}$ is observed pension income from disability insurance. $X_{i, t}$ is a set of covariates.

The retirement model was estimated by logistic regression with maximum likelihood estimation. Given the value functions of working and retiring in (13) and (14), the probability of retiring is therefore:

$\operatorname{Pr}\left(R_{i, t}\right)=\frac{\exp \left(V_{R, i, t}-V_{W, i, t}\right)}{1+\exp \left(V_{R, i, t}-V_{W, i, t}\right)}$
To evaluate the effects of pension reform on prolonging working life, we predicted the potential retirement outcomes based on our estimated retirement model, given the two scenarios of pension benefits (with and without reform), respectively. The scenario with the reform is essentially the predicted probability given the values of retiring and working determined by all the covariates as observed. Let $\hat{p}$ be such a predicted probability, thus:

$$
\begin{aligned}
\hat{p}_{i, t}= & \operatorname{Pr}\left\{R_{i, t} \mid V_{W, i, t}\left(Y_{i, t}, X_{i, t}, \alpha, \gamma_{W}\right),\right. \\
& \left.V_{R, i, t}\left(E\left(O A_{i, t} \mid t, c, Z_{i}, S_{i, t}, \theta\right), D I_{i, t}, X_{i, t}, \beta, \gamma_{R}\right)\right\}
\end{aligned}
$$

The scenario of without reform is the probability conditional on the values of retiring and working determined by all the covariates as observed except the expected old-age pension benefits. The cohort variable in (14) in this scenario is imposed by $c=1937$. Doing this allows for estimating what the value of retiring, as well as the retirement probability, would have been had the pension income for all cohorts been calculated based on the pre-reform accounting rule, ATP. Let $p^{*}$ be such a probability, therefore:

$$
\begin{aligned}
p_{i, t}^{*} & =\operatorname{Pr}\left\{R_{i, t} \mid V_{W, i, t}\left(Y_{i, t}, X_{i, t}, \alpha, \gamma_{W}\right), V_{R, i, t}\left(E \left(O A_{i, t} \mid t, c\right.\right.\right. \\
& \left.\left.\left.=1937, Z_{i}, S_{i, t}, \theta\right), D I_{i, t}, X_{i, t}, \beta, \gamma_{R}\right)\right\}
\end{aligned}
$$

To examine the statistical significance of the effects of pension reform on retirement, we also calculated the confidence intervals associated with $\hat{p}_{i, t}$ and $p_{i, t}^{*}$. These intervals were calculated by:

$$
C I_{\operatorname{Pr}\left(R_{i, t}\right)}=\frac{\exp \left(\widehat{\xi_{V_{i, t}}}+1.96 \sigma_{\xi_{v_{i, t}}}\right)}{1+\exp \left(\widehat{\xi_{V_{i, t}}}+1.96 \sigma_{\xi_{V_{i, t}}}\right)}
$$

where, $\widehat{\xi_{V_{i, t}}}=\widehat{V_{R, i, t}}-\widehat{V_{W, i, t}} \cdot \widehat{V_{R, i, t}}$ and $\widehat{V_{W, i, t}}$ are the linear prediction of value of retiring and working using (14) and (13), respectively. $\sigma_{\xi_{V_{i, t}}}$ is the standard errors of $\xi_{V_{i, t}}$.

The standard errors of $\xi_{V_{i, t}}$ were estimated by:

$\sigma_{\xi_{i, t}}=\sqrt{g_{i, t}^{\prime}(-H)^{-1} g_{i, t}}$

where, $g_{i, t}$ is the gradient and $H$ is the Hessian matrix; they were retrieved from the maximum likelihood estimation.

\section{Calculating mean retirement age}

We used the potential retirement probabilities, $\hat{p}$ and $p^{*}$, as well as their confidence intervals to calculate the average effective age of labor market exit in the economy with and without the old-age pension reform, respectively. The two mean retirement ages were calculated using the method of dynamic exit age indicator in Vogler-Ludwig and Dull (2008). The derivation is briefly presented as the following. Let $\hat{p}_{i, t}$ be the probability of retiring for an individual at age $t$, which is predicted by our retirement model, Eq. (15). The probability of remaining in the labor force at age $t$ is defined as the overall probability of staying in the labor force from some starting age $t_{0}$ up to age $t-1$ (Vogler-Ludwig and Dull, 2008). In the present context, we assume $t_{0}=59$, and this probability may be written as:

$p_{i, t}^{s}=\prod_{i=59}^{t-1}\left(1-\hat{p}_{i, t}\right)$

The probability of exiting the labor force at age $t$ is then the probability of retiring at age $t$ (i.e. $\hat{p}_{i, t}$ ), given the overall probability of remaining in the labor force up to age $t-1$ (i.e. $p_{i, t}^{s}$ ). The average effective labor market exit age is then computed as the sum of ages weighted by the probability of exiting the labor force. The age range in our case is assumed to be between 59 and 67. Therefore, the average exit age may be explicitly written as: 
Table 2

Sample characteristics and mean differences between gender.

\begin{tabular}{|c|c|c|c|c|}
\hline Variables & Men & Women & Diff & ( $p$-value) \\
\hline Retire & 0.16 & 0.17 & -0.01 & 0.00 \\
\hline Labor income & 270,527 & 187,817 & 82,710 & 0.00 \\
\hline Predicted pension & 63,530 & 52,311 & 11,218 & 0.00 \\
\hline Counter-factual pension & 74,917 & 51,838 & 23,078 & 0.00 \\
\hline Age & 62.68 & 62.61 & 0.07 & 0.00 \\
\hline Married & 0.71 & 0.65 & 0.06 & 0.00 \\
\hline Primary & 0.34 & 0.29 & 0.05 & 0.00 \\
\hline Secondary & 0.40 & 0.42 & -0.01 & 0.00 \\
\hline University & 0.26 & 0.30 & -0.04 & 0.00 \\
\hline High-skill & 0.52 & 0.40 & 0.12 & 0.00 \\
\hline Low-skill service & 0.09 & 0.47 & -0.38 & 0.00 \\
\hline Low-skill manual & 0.39 & 0.13 & 0.25 & 0.00 \\
\hline Observations & $1,781,701$ & $1,661,793$ & & \\
\hline
\end{tabular}

$e_{i}=\sum_{i=59}^{67} \hat{p}_{i, t} \times p_{i, t}^{s} \times t$

Fig. 2 illustrates the calculated average effective labor market exit age for each consecutive cohort born between 1937 and 1944. The mean exit age from the labor market exhibits a clear upward trend for each successive cohort for both sexes. This cohort trend coincides with what was shown in Karlsson and Olsson (2012). However, our calculated retirement ages are higher than in Karlsson and Olsson (2012), because our sample conditioned on still being in the labor force at age 59, whereas their sample conditioned on age 50. The difference between the oldest and youngest cohort in average retirement age is 0.47 for men and 0.56 for women. In other words, the shifting age pattern shown in Fig. 1 implies that those born in 1944 retired on average 5.7 months for men and 6.7 months for women later than those born in 1937 who were unaffected by the pension reform, and whose benefits were entirely calculated based on the ATP rule.

Eq. (21) was applied to calculate the predicted and counterfactual mean exit age using $\hat{p}_{i, t}, p_{i, t}^{*}$. The effect of the gradual phasing in of NDC on prolongation of working life is therefore the difference between the average retirement age calculated by $\hat{p}_{i, t}$ and $p_{i, t}^{*}$. More explicitly:

$d E(e)=E\left(e \mid \hat{p}_{i, t}\right)-E\left(e \mid p_{i, t}^{*}\right)$

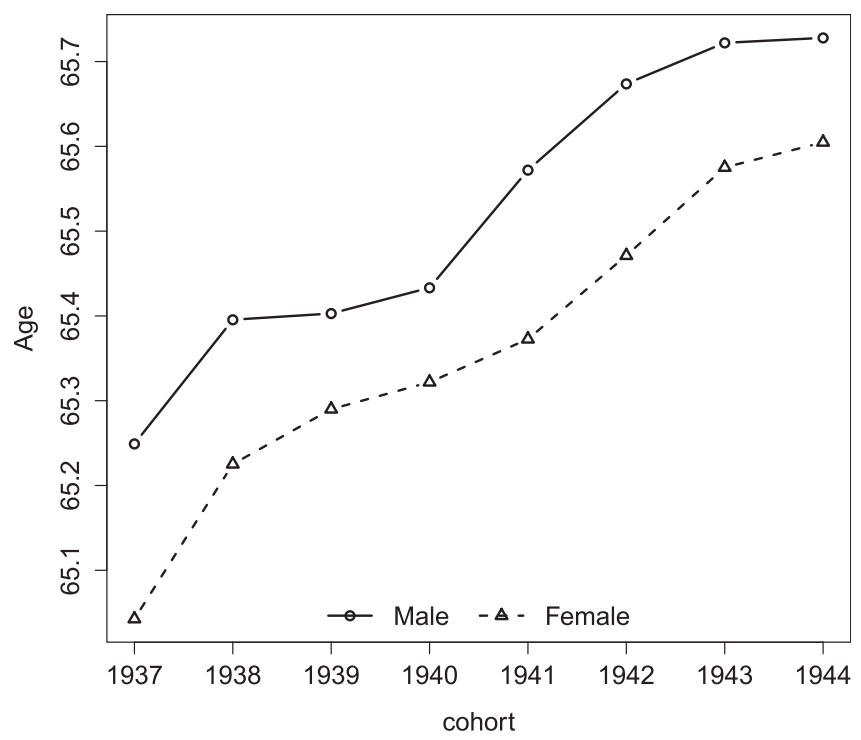

Fig. 2. Cohort trends in retirement age conditional on working at age 59 .
The basic argument is that if NDC prolongs working life, $d E(e)$ should be large and positive. For example, if the differences in the average retirement age between the 1937 and 1944 cohort are indeed the consequence of NDC, we shall expect $d E(e)$ to be close to 0.47 for men and 0.56 for women.

\section{Results}

This section reports and discusses our major findings of the analysis. We start by showing the differences in the age profiles of pension income across cohorts, both observed $\left(O A_{i, t}\right)$ and predicted pension $\left(E\left(O A_{i, t} \mid t, c, Z_{i}, S_{i, t}, \theta\right)\right)$ using Eq. (12). We then show the simulated counter-factual pension income assuming all cohorts belonging to the ATP system, which is computed by imposing $c=1937$ in (12). The predicted pension income $E\left(O A_{i, t} \mid t, c, Z_{i}, S_{i, t}, \theta\right)$ is used for estimating the retirement model, and the coefficient estimates and model fit are illustrated in the later part of this section. Finally, the effects of the pension reform on retirement age are quantified and reported.

\section{Predicted and counter-factual pension}

Table 3 provides the coefficient estimates for the pension Eq. (12), which are then used to predict the expected and counterfactual pension benefits. Fig. 3 depicts the observed and fitted pension income based on the estimates in Table 3. All the values were adjusted for inflation to 2011 price levels. The black lines in Fig. 3 are the observed and predicted pension incomes for men, and the dark gray lines are for women. The first thing to note is that the predicted benefits by our pension forecasting equation fits the observed age profiles of old-age pension income extremely well. The goodness of fit of our pension forecasting equation is particularly important for simulating the counter-factual pension benefits and retirement age, which are shown in the later part of this section.

The second important note is that, within each cohort, gender differences in pension entitlements are considerable, as indicated by the discrepancies between the black and gray lines. However, such discrepancies are much more profound within the 1937 cohort than all younger ones. This is mainly due to the differences in the benefit accounting between the ATP and NDC system. The 1937 cohort was the last birth cohort who fully belonged to the ATP system, thus the best-15-year rule applied to calculate their full benefits. As we mentioned earlier, the 15-best-year rule generated significant redistribution from low- to high-income earners and from women to men, because the peak of the life-cycle earning profile is higher for men and high-income earners. Therefore, the 
Table 3

Parameter estimates of pension equation.

\begin{tabular}{|c|c|c|}
\hline Variables & Men pension & Women pension \\
\hline Constant & $34,044^{* * *}$ & $42,793^{* * *}$ \\
\hline$\sum_{i=55}^{t-1} Y(t)$ & $0.003^{* * *}$ & $0.005^{* * *}$ \\
\hline Married & $3125^{* * *}$ & $-20,073^{* * * *}$ \\
\hline High-skill & \multicolumn{2}{|c|}{ Ref. } \\
\hline Low-skill service & $-10,836^{* *}$ & -2844 \\
\hline Low-skill manual & -4894 & $-5647^{* *}$ \\
\hline Primary education & \multicolumn{2}{|c|}{ Ref. } \\
\hline Secondary education & 2335 & 1050 \\
\hline University + education & $6185^{*}$ & 2491 \\
\hline Sweden & \multicolumn{2}{|c|}{ Ref. } \\
\hline Africa & $-20,335^{* * *}$ & -3577 \\
\hline Asia & $-25,854^{* * *}$ & $-11,171^{* * *}$ \\
\hline Balkan & $-16,503^{* * *}$ & $-7095^{* * *}$ \\
\hline Europ excl. nordic & $-9170^{* * *}$ & $-6009^{* * *}$ \\
\hline Middle east & $-31,693^{* * *}$ & $-16,505^{* * *}$ \\
\hline Nordic excl. Sweden & $-4816^{* * *}$ & $-3887^{* * *}$ \\
\hline North America & $-29,150^{* * *}$ & $-21,327^{* * *}$ \\
\hline South America & $-30,666^{* * *}$ & $-19,316^{* * *}$ \\
\hline Age & \multicolumn{2}{|c|}{ Yes } \\
\hline Cohort & \multicolumn{2}{|c|}{ Yes } \\
\hline Age $\times$ cohort & \multicolumn{2}{|c|}{ Yes } \\
\hline Age $\times$ cohort $\times$ occupation & \multicolumn{2}{|c|}{ Yes } \\
\hline Age $\times$ cohort $\times$ education & \multicolumn{2}{|c|}{ Yes } \\
\hline Observations & 254,770 & 316,522 \\
\hline$R$-squared & 0.429 & 0.322 \\
\hline
\end{tabular}

Significance: ${ }^{* * *} p<0.01,{ }^{* *} p<0.05,{ }^{*} p<0.1$.

Note: Age and cohort are dummy indicators.

benefit differences are the greatest for the 1937 cohort in Fig. 3. As the younger cohorts became more attached to the NDC system, whereby the peak of the life-cycle earning profile became less important for calculating the benefits, the gender differences in pension income diminished.

The third noteworthy feature in Fig. 3 is that the benefits between age 60 and 65 were nearly flat for the 1937 cohort who belonged to the ATP system, but became a steeper increasing function of age for later born, particularly among the last two birth cohorts, whose benefits were $45 \%$ and $50 \%$ derived from NDC, respectively. This is in line with Laun and Wallenius (2015) who argued that the pension benefits over age were very flat in the old system, but increased much more steeply as a function of age in the new system.

The steep growth curve of pension income for younger cohorts is also associated with the divisor in benefit accounting in NDC. As we stressed earlier, one important feature distinguishing NDC from ATP is the divisor to calculate the annuity. The divisor is a function of remaining life expectancy which is determined by age and cohort, not by gender and previous earning history. This divisor, however, implies benefit reduction for those who participated in the NDC system (for those born in 1938 or later). As long as life expectancy increases, the younger generation will receive ever decreasing monthly pension benefits since the divisor is an increasing function of remaining years of living (Hagen, 2013). This is particularly important for retirement income between ages 60 and 64 , since from age 65 , workers will be able to claim guaranteed pension, which can potentially top up monthly pension benefits. Therefore, the growth curves in pension income between age 60 and 65 for the two youngest cohorts are much steeper than for their older counterparts.

Fig. 4 shows the difference between the predicted and counterfactual pensions by age and cohorts. For the counter-factual, shown by the dash lines in Fig. 4, it is assumed that all later born cohorts expected to receive the same benefit level as the 1937 cohort. That is every one received $100 \%$ ATP pension, and thus
1937

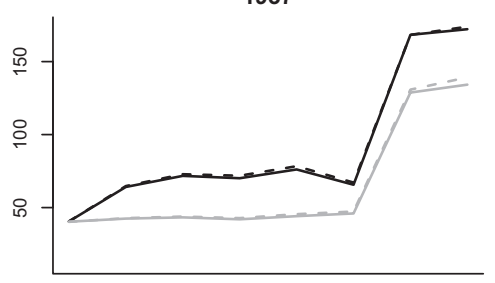

1940

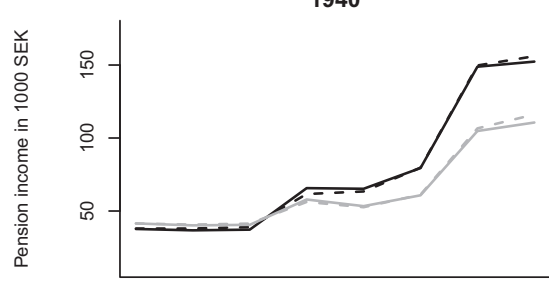

1943

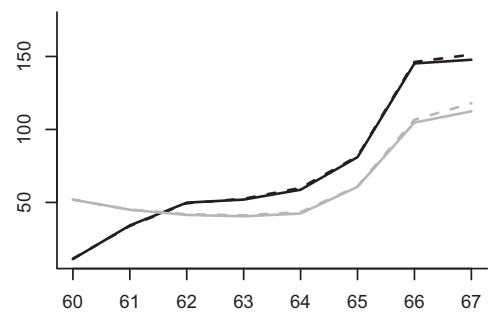

1938

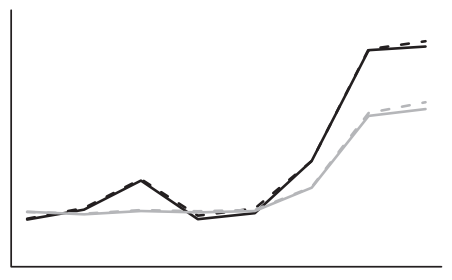

1941

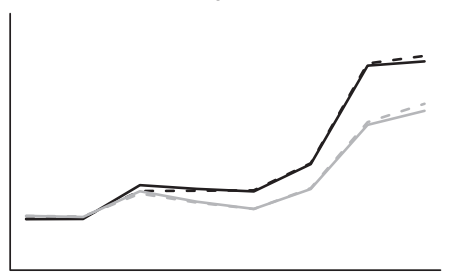

1944

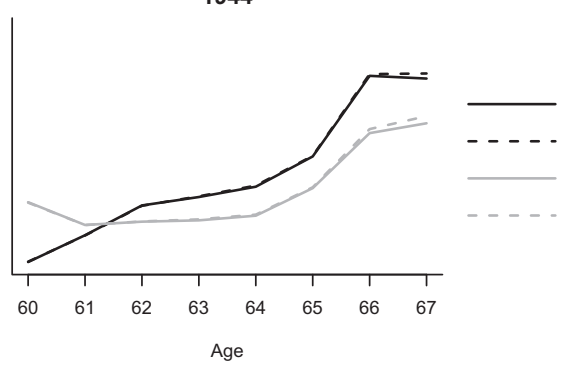

1939

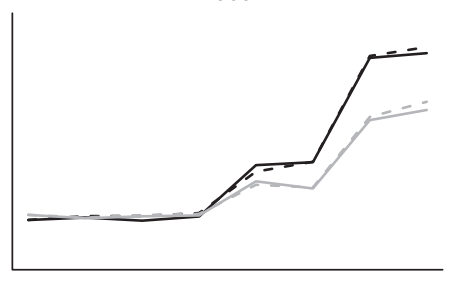

1942

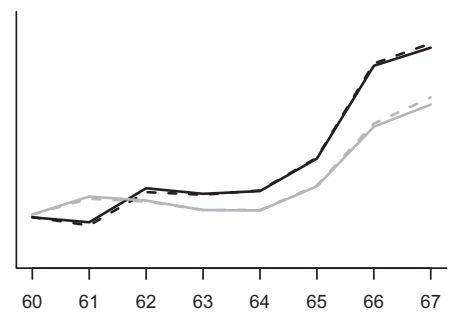

Male Obs.

Male Fit.

Female Obs.

Female Fit

Fig. 3. Observed and predicted pension income in $1000 \mathrm{SEK}$. Note: observed is the mean of $O A_{i, t}$, and predicted is the mean of $E\left(O A_{i, t} \mid t, c, Z_{i}, S_{i, t}, \theta\right)$. 
1937

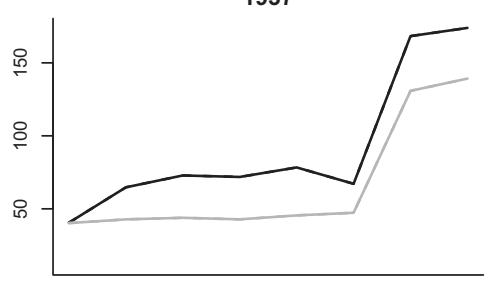

1940

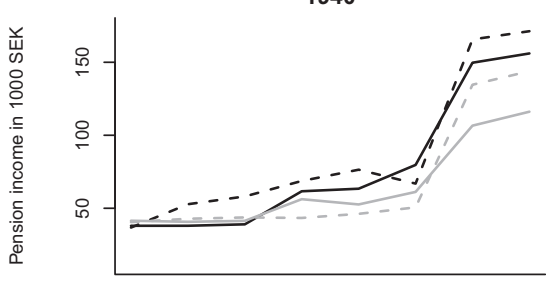

1943

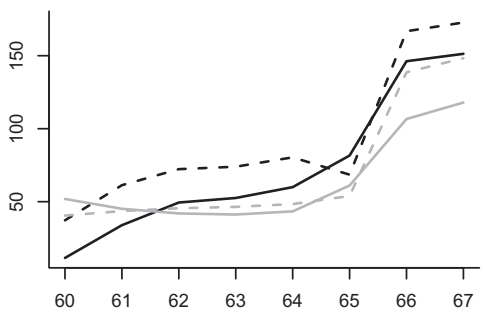

1938

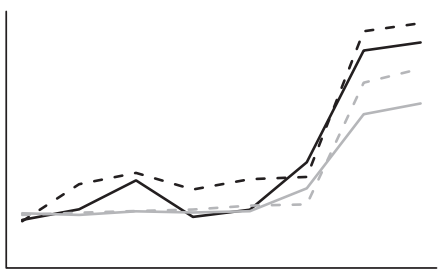

1941

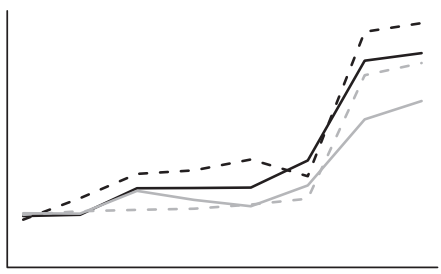

1944

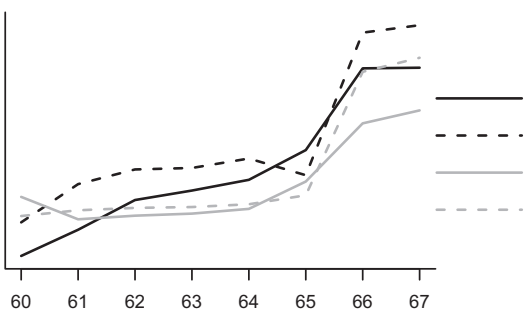

1939

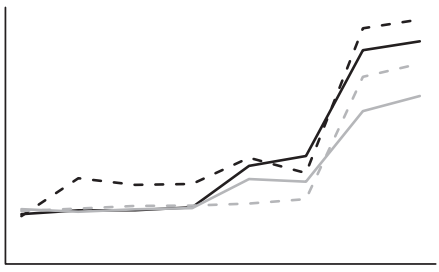

1942

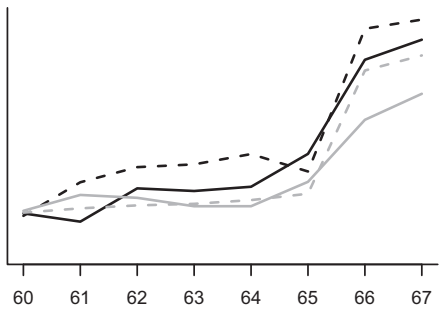

Male Fitted

Male Couter.

Female Fitted

Female Counter.

Age

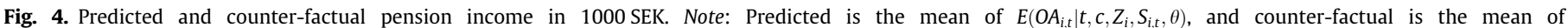
$E\left(O A_{i, t} \mid t, c=1937, Z_{i}, S_{i, t}, \theta\right)$.

the benefits over age would be flat compared to the NDC pension. The difference between the dash lines and the solid lines reflects the amount of pension reduction due to the 1994 pension reform.

Two features are worth noting in Fig. 4. First, the reform resulted in much greater benefit reduction for men than women, as the difference between the dash and solid lines is larger for men. Such differences in benefit reduction reflect the difference between ATP and NDC in benefit accounting. As discussed earlier, the best-15-year rule in ATP generated the redistribution from women to men, whereas NDC mitigated such unequal redistribution. The consequence is, as shown in Fig. 4, that men lost more in pension entitlements than women over the reform. This is because NDC reversed the redistribution flow from low- to highincome earners compared to the old system.

The second important note from Fig. 4 is that the benefit reduction for men, depicted by the black dash and solid lines, implies that for those more attached to NDC, were they to have retired at the same age under the ATP system, the implied pension income would have been much lower, a finding in line with the argument in Laun and Wallenius (2015).

Fig. 5 shows the percentage change in the pension benefits due to phasing in the NDC scheme for each cohort. The reduction is greater for men than women. Men born in 1944, on average, loss over $10 \%$ in their benefits, whereas women born in the same year loss about 6\%. In addition, among those women born in 19391941 , their pension benefits were actually increased by around $2 \%$. These gender differences in pension change due to the reform, once again, reflect the differences in benefit accounting between ATP and NDC. As mentioned previously, the best-15-year rule in ATP redistributes income from women to men, because the peak of the life-cycle earning profile is typically higher for men than women. NDC treats workers with equivalent lifetime earnings, but inequivalent earning profiles, equally by taking full lifetime earnings into account for calculating benefits. And consequently, it reversed the women to men (as well as high to low income earner) redistribution that originally existed in ATP.

The remainder of this paper will examine, to what extent, the cohort trend in retirement age shown in Fig. 2 can be explained by the cohort differences in pension benefits shown in Fig. 5.

\section{Retirement model estimates}

We estimated the retirement model, as specified in (13) and (14), by alternative-specific logistic regression. The variables included in the non-pecuniary value function $\left(X_{i, t}\right)$ are age and cohort dummies. Due to the large number of coefficient estimates for these dummies, as well as their interactions, we suppress these estimates and only report the parameters for labor and pension in Table 4.

The labor and pension income coefficients correspond to $\alpha$ and $\beta$, respectively. They are essentially the marginal utility of labor income while working and of pension benefits while retiring. For example, the coefficients reported here can be interpreted as an increase in 100,000 SEK from labor income would increase the utility of working by 1 SEK for men and 2 SEK for women. The same amount increase in pension income would raise the value of retiring by 4 SEK for both gender.

Since $\alpha$ and $\beta$ are the marginal utility of labor income and pension, respectively, the ratio of $\beta$ to $\alpha$ gives the marginal rate of substitution of pension in terms of labor income, which is 4 for men and 2 for women. This implies that, in order to retire, men would 


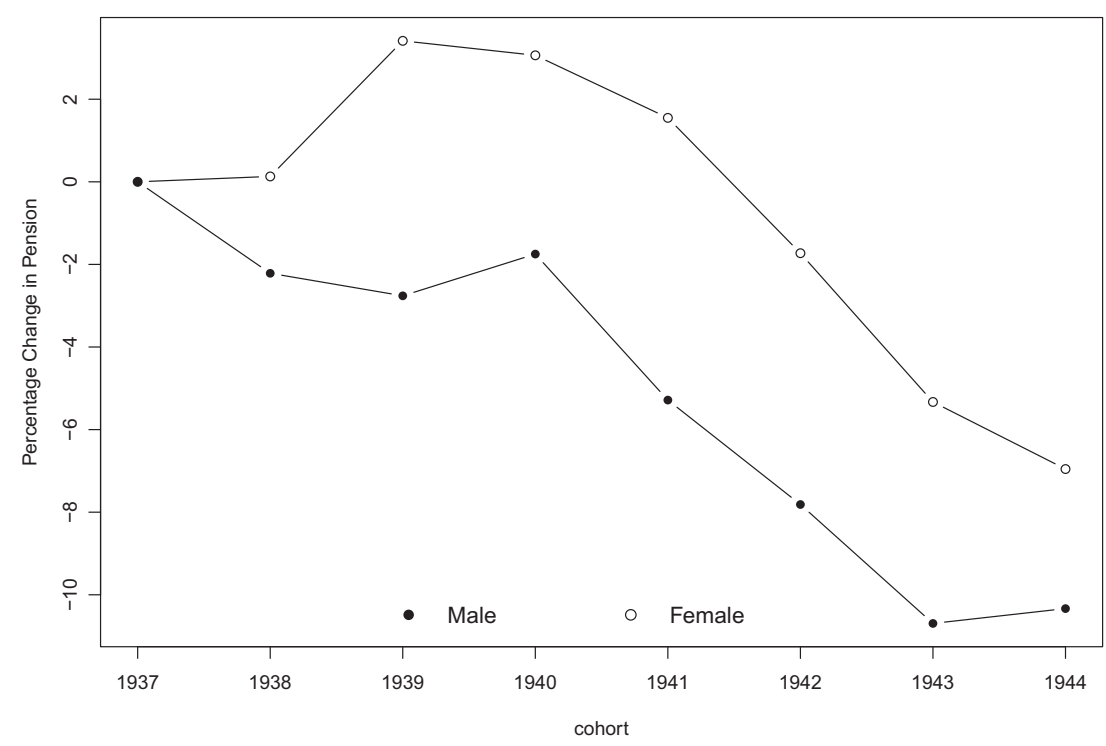

Fig. 5. Changes in pension due to phasing in NDC.

Table 4

Model estimates for Eq. (15) by alternative-specific logistic regression.

\begin{tabular}{lll}
\hline Variables & \multicolumn{2}{c}{ Choice: retire } \\
\cline { 2 - 3 } & Men & Women \\
\hline Constant & $-2.542^{* * *}$ & $-1.677^{* * *}$ \\
Labor & $0.00001^{* * *}$ & $0.00002^{* * *}$ \\
Pension & $0.00004^{* * *}$ & $0.00004^{* * *}$ \\
Age & Yes & Yes \\
Cohort & Yes & Yes \\
Age $\times$ cohort & Yes & Yes \\
Observations & $1,781,701$ & $1,661,793$ \\
$R^{2}$ & 0.537 & 0.567 \\
Log likelihood & $-359,062$ & $-327,068$
\end{tabular}

Significance: ${ }^{* * *} p<0.01,{ }^{* *} p<0.05,{ }^{*} p<0.1$.

be willing to give up 4 SEK from labor income for each SEK obtainable from pension, while the respective figure for women is 2 SEK. In other words, men have a stronger preference for retirement than women, which might sound contradictory given that men are on average always retire at older age than women, as shown in Fig. 2. However, this stronger preference is mainly driven by the fact that men earn more from work than women, as shown in Table 2, men's labor income is $40 \%$ greater than women's, whereas their pension is merely $20 \%$ higher.

\section{The effect of NDC on retirement age}

Using the parameter estimates in Table 4, we compute the predicted and counter-factual retirement probabilities ( $\hat{p}$ and $p^{*}$ ). These probabilities are then used to calculate the mean effective labor market exit age using (21). Fig. 6 illustrates the observed, predicted, and counter-factual average retirement age by cohort. The dots represent the retirement age implied by the predicted probabilities $(\hat{p})$, which overlaps with the observed retirement age (shown by gray solid line). This indicates that the predicted pension based on the estimates reported in Table 3 together with the retirement model estimates (shown in Table 4) replicate the cohort pattern of the average retirement age remarkably well. This goodness of fit is crucial for the counter-factual retirement age implied by $p^{*}$ to be comparable with the actual retirement age. The circles in Fig. 6 represent the counter-factual retirement age, which illustrates what the average retirement age would have been, if the cohort differences in pension benefits are none.

The effect of phasing in NDC during the 1994 pension reform on retirement age is the difference between the mean age at labor market exit implied by the predicted and counter-factual retirement probabilities, as per Eq. (22). This difference is illustrated in Fig. 7, which suggests that, while the retirement age for men and women exhibits an upward cohort trend in Fig. 2, as was the case in Karlsson and Olsson (2012), the underlying causes appear to be different between sexes.

For men, the growth in labor market exit age across cohorts seems largely driven by the 1994 pension reform, as the difference between the predicted and counter-factual retirement age is large and statistically different from zero. The difference also increases over cohorts, which makes intuitive sense because NDC was gradually phased in across these transitional cohorts. The effects of the reform on the retirement age was greater for younger cohorts because they were more attached to the NDC pension system, which created stronger incentives to work longer. For example, NDC prolonged working life by 0.15 year (or roughly 2 month) for the 1944 cohort. Recalling that the total difference in retirement age between the 1944 and 1937 cohort was 0.47 (shown in Fig. 2), NDC explained about one-third of this total difference for this particular cohort.

For women, however, the reform effect on the retirement age was much less profound than for men. Taking the youngest female cohort as an example, the effect of NDC on retirement age is merely 0.03 year, or 0.36 month. Given the total difference in the average retirement age between the 1937 and 1947 cohort ( 0.56 year), NDC merely explained $5.5 \%$ of the total difference. In fact, the positive effect of the reform emerged only among those born in 1942 and later. For earlier born cohorts, the reform actually exerted a negative effect on the mean retirement age, and such an adverse impact was statistically significant for the 1939 and 1940 cohorts. However, this negative effect might not be unexpected. As shown in Fig. 5, women born in 1939 and 1940 actually gained over 2\% in pension benefits, which accordingly elevated the value of retirement relative to work, as well as the probability of retiring. As a result, the average age at retirement was lower than it otherwise would have been had the reform not occurred.

In general, the small and opposite effect of NDC on female mean retirement age suggests that the upward cohort trend may have 


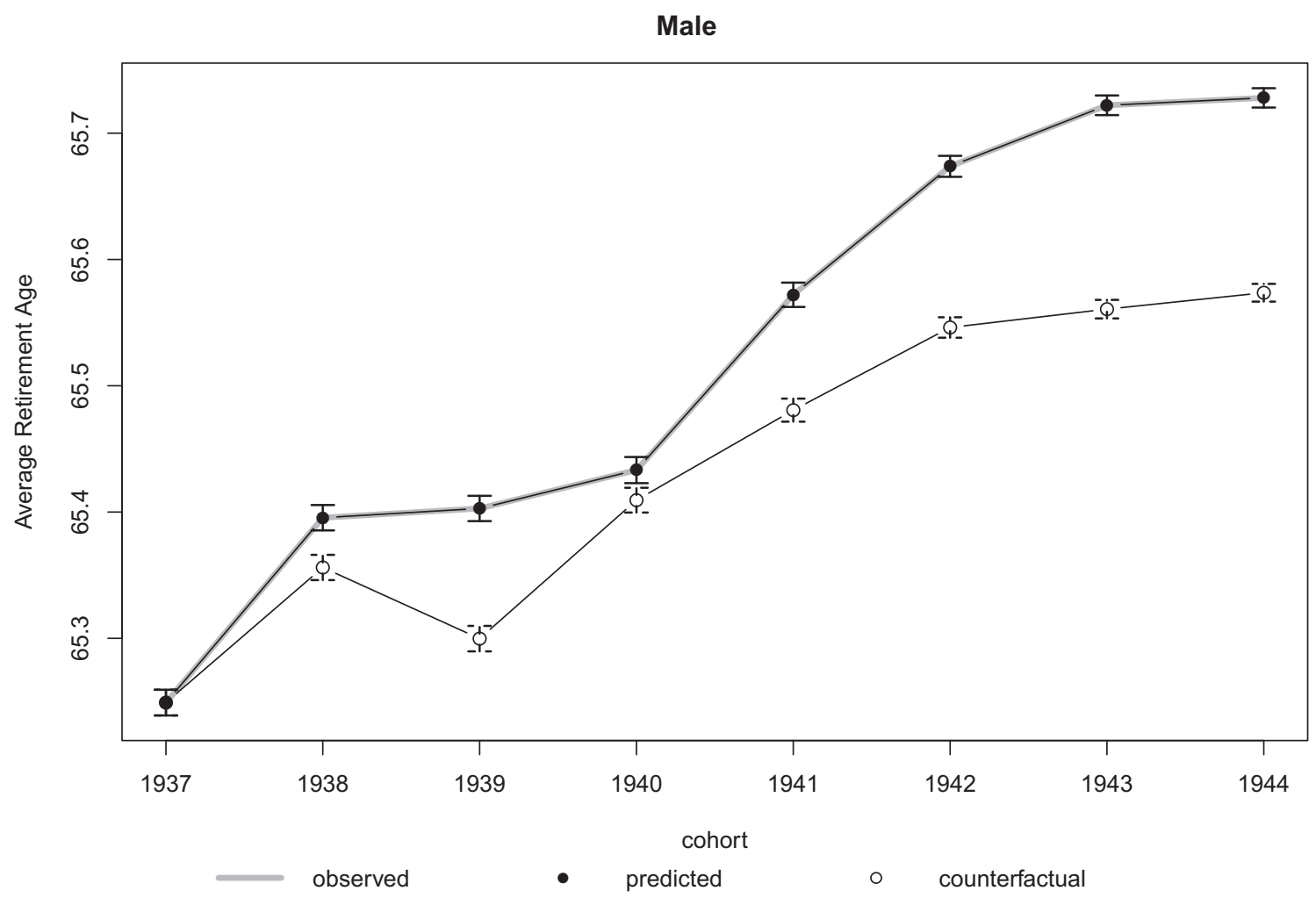

Female

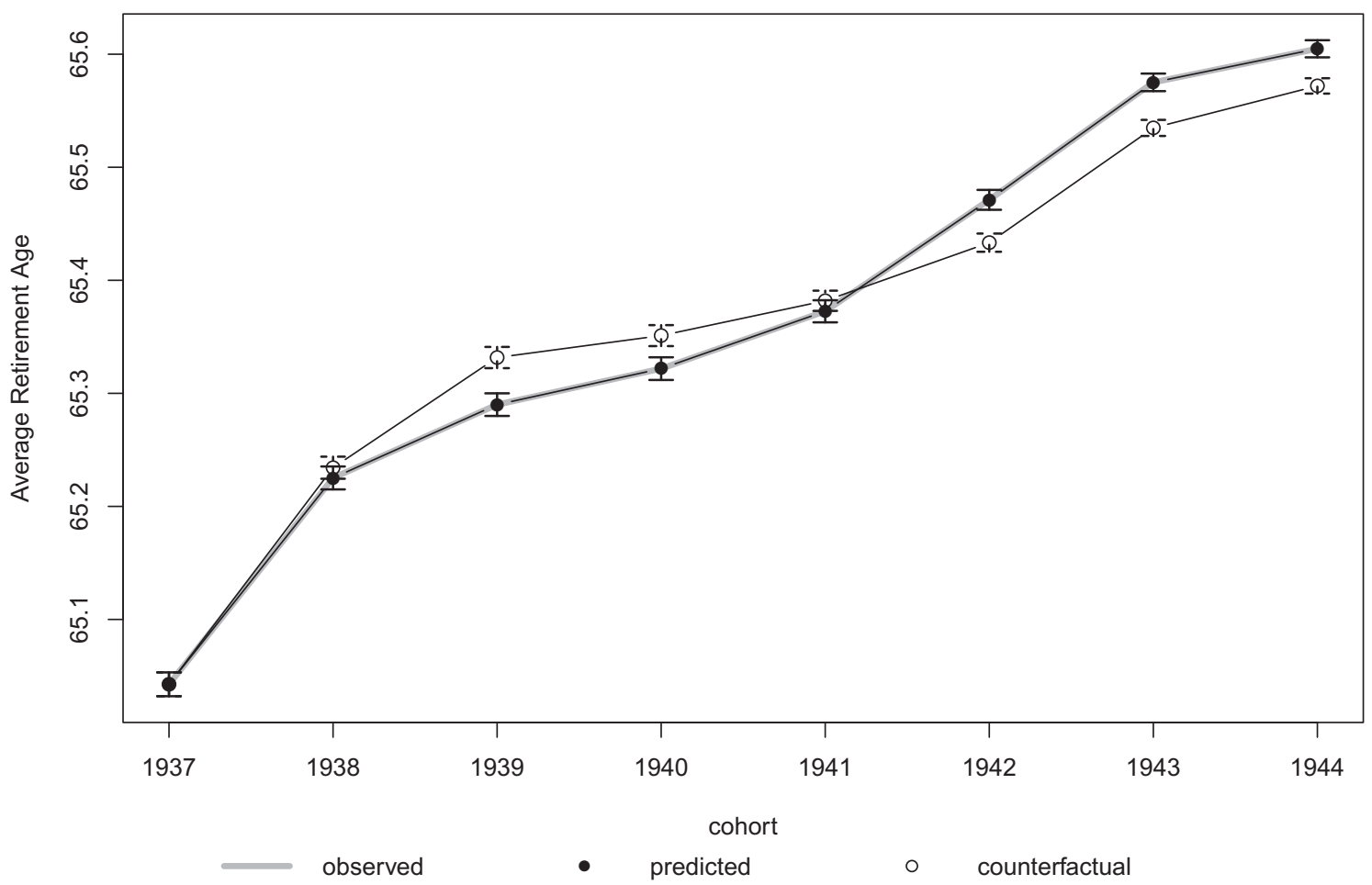

Fig. 6. Average retirement age over cohorts.

been driven by other factors which are independent of economic incentives. In other words, women's average labor market exit age would have been increasing anyway even though the reform was not in place. For men, however, the increasing mean retire- ment age across cohorts was substantially, although not completely, driven by the changing financial incentives mediated by the gradual phasing in of NDC. In brief, the 1994 Swedish pension reform which phased in the NDC system did not create a universal 

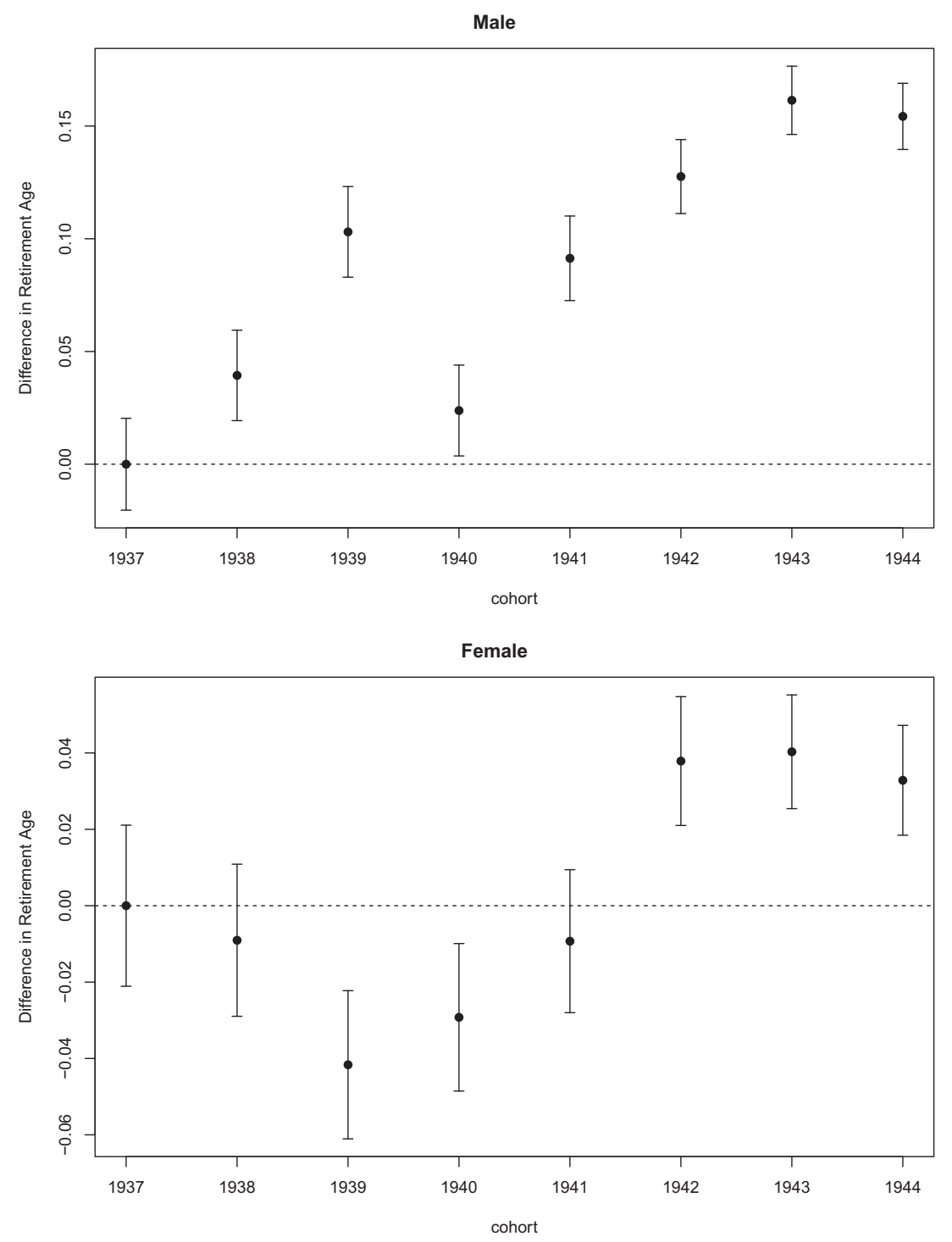

Fig. 7. Effects of NDC on retirement age over cohorts.

incentive for all older workers to postpone their retirement, the results here rather suggest a considerable gender difference in terms of responses to a macro policy change.

\section{The effect of NDC on the "New Labor Market"}

To date, we have presented our results in terms of the average impact of the 1994 pension reform on retirement age. The effects of policy change on potentially vulnerable groups (the so-called "new labor market") are currently of great interest to researchers and policy makers. The final part of our analysis addresses the question of whether the group with less education attainment and low-skill occupation respond to a macro-level institutional change in the same way as their highly educated and skilled counterparts?.

Fig. 8 illustrates the observed, predicted, and counter-factual average retirement age by cohort and educational attainment. The retirement age implied by the predicted probabilities (dots) nearly overlaps with the observed retirement age (shown by gray solid line). This indicates that calibrating the parameter estimates in Table 3 and 4 into the retirement model (16) replicates the cohort pattern in the average retirement age fairly well for each educational group. Such an accurate prediction ensures that the counter-factual retirement age generated by Eq. (17) (which eliminates the cohort differences in pension benefits reported in Table 3 ) is comparable with the actual retirement ages across different birth cohorts and education groups.

The first insight from Fig. 8 is that the upward trend of predicted and observed retirement age persists across all education and gender groups, a pattern similar to what was found in Qi et al. (2016) and Qi, 2016. ${ }^{2}$ This suggests that later born cohorts almost universally work longer compared to their older counterparts, regardless of gender and education attainment, although the level differences in retirement age still exist. However, the magnitude of the discrepancies between the predicted (dots) and counter-factual (circles) retirement age varies across different education groups, suggesting that the underlying mechanisms driving these universal trend increases are not the same.

Fig. 9 illustrates the effect of the NDC on the retirement age for each education level. It is clear that the effect of phasing in the NDC

\footnotetext{
${ }^{2}$ Qi et al. (2016) and Qi (2016) showed a universal trend increase in the average retirement age across individuals of different health status, education, and country of birth.
} 

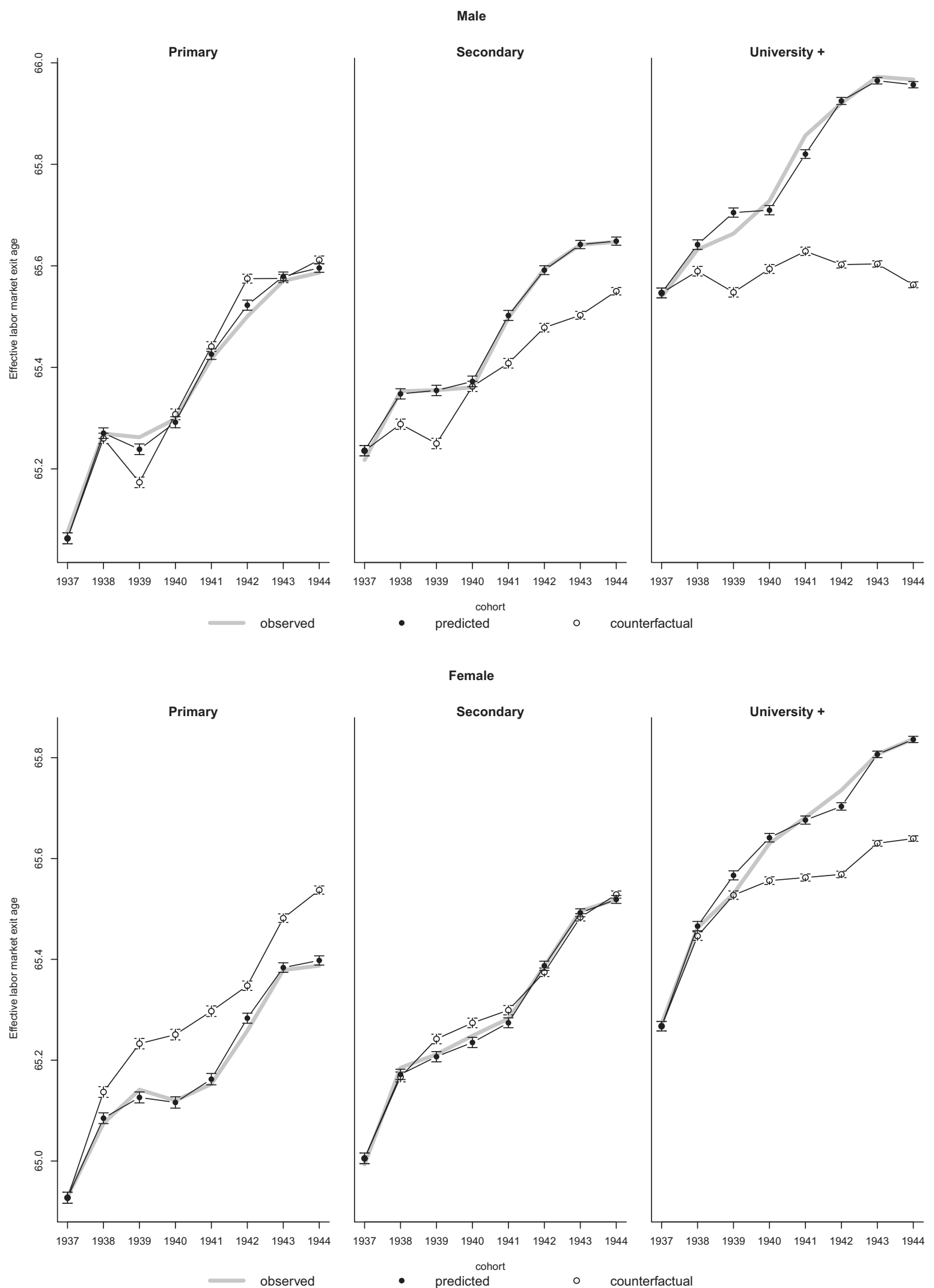

Fig. 8. Average retirement age by educational attainment.

is large among those highly educated (university + education), which increases almost linearly across cohorts. As mentioned previously, this enlarging effect over cohorts makes intuitive sense because NDC was gradually phased in across these transitional cohorts. As younger cohorts were more attached to the NDC pension system, incentives to work longer become accordingly stronger. If we compare the 1944 cohort with the 1937 cohort, the prolongation of working life solely due to NDC is 0.4 year and 

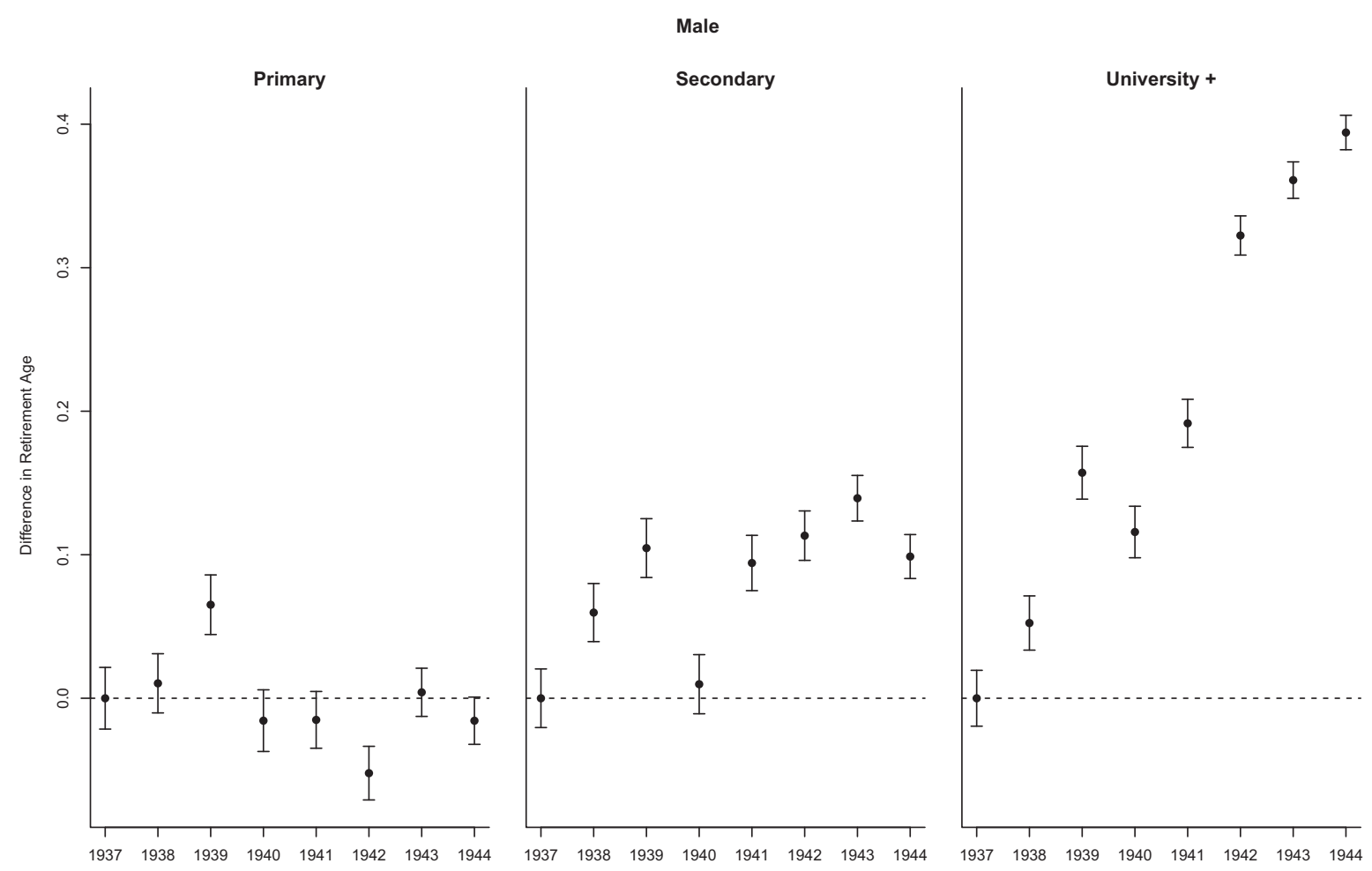

cohort
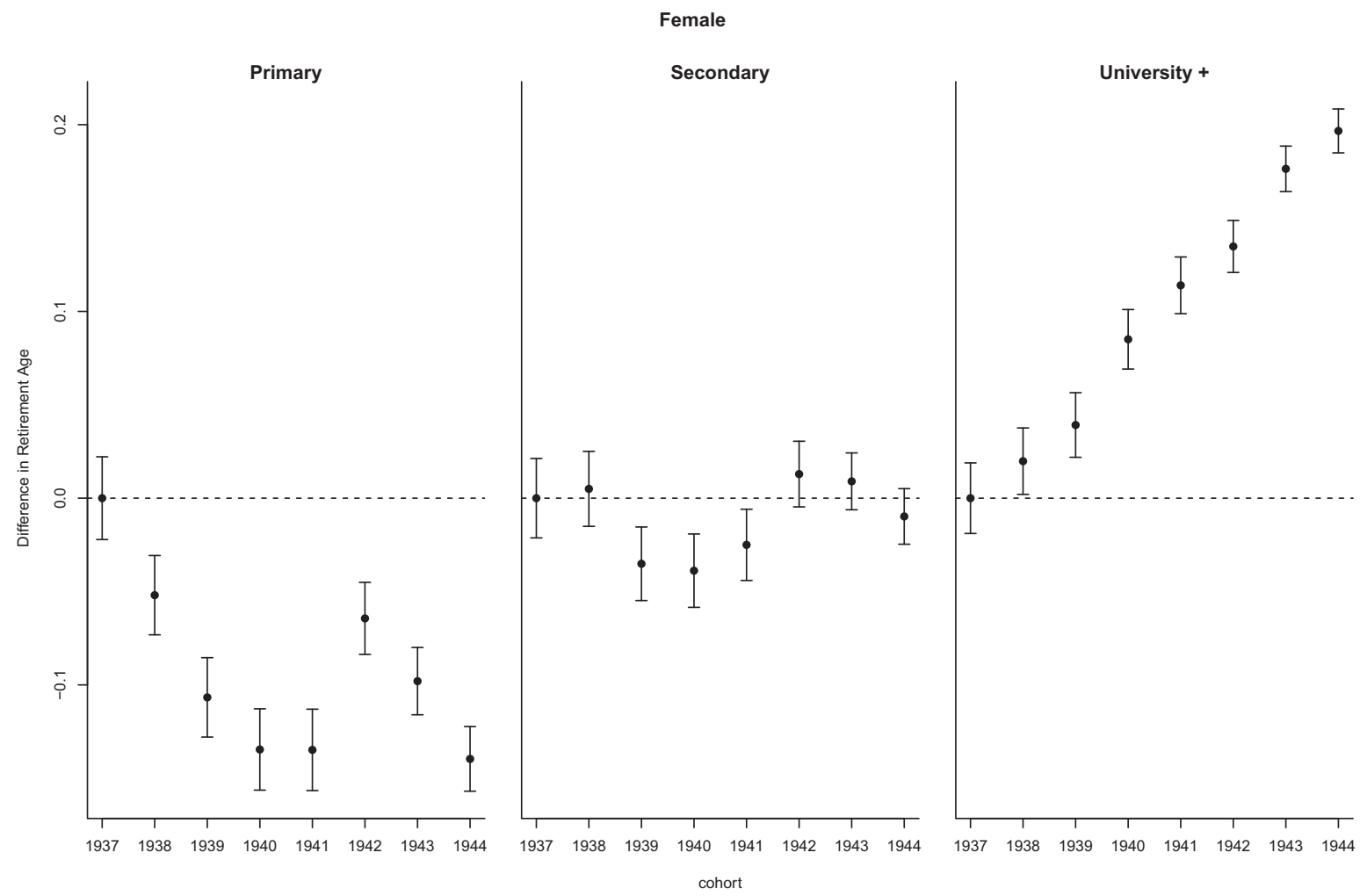

Fig. 9. Effect of NDC on average retirement age by educational attainment.

0.2 year for highly educated men and women, respectively. However, such a strong and statistically significant effect does not exist among those attained lower education levels. In particular, among those who only attained primary education, the effects are mostly negative (and even statistically significant for women).
Fig. 10 compares the cohort trends of observed retirement age with the predicted and counter-factual ones for each occupational group. The goodness of fit is poor for male with low-skill service. This is mainly because men engaged in this sector is only $9 \%$, a much smaller proportion compared to the high-skill white-collar 


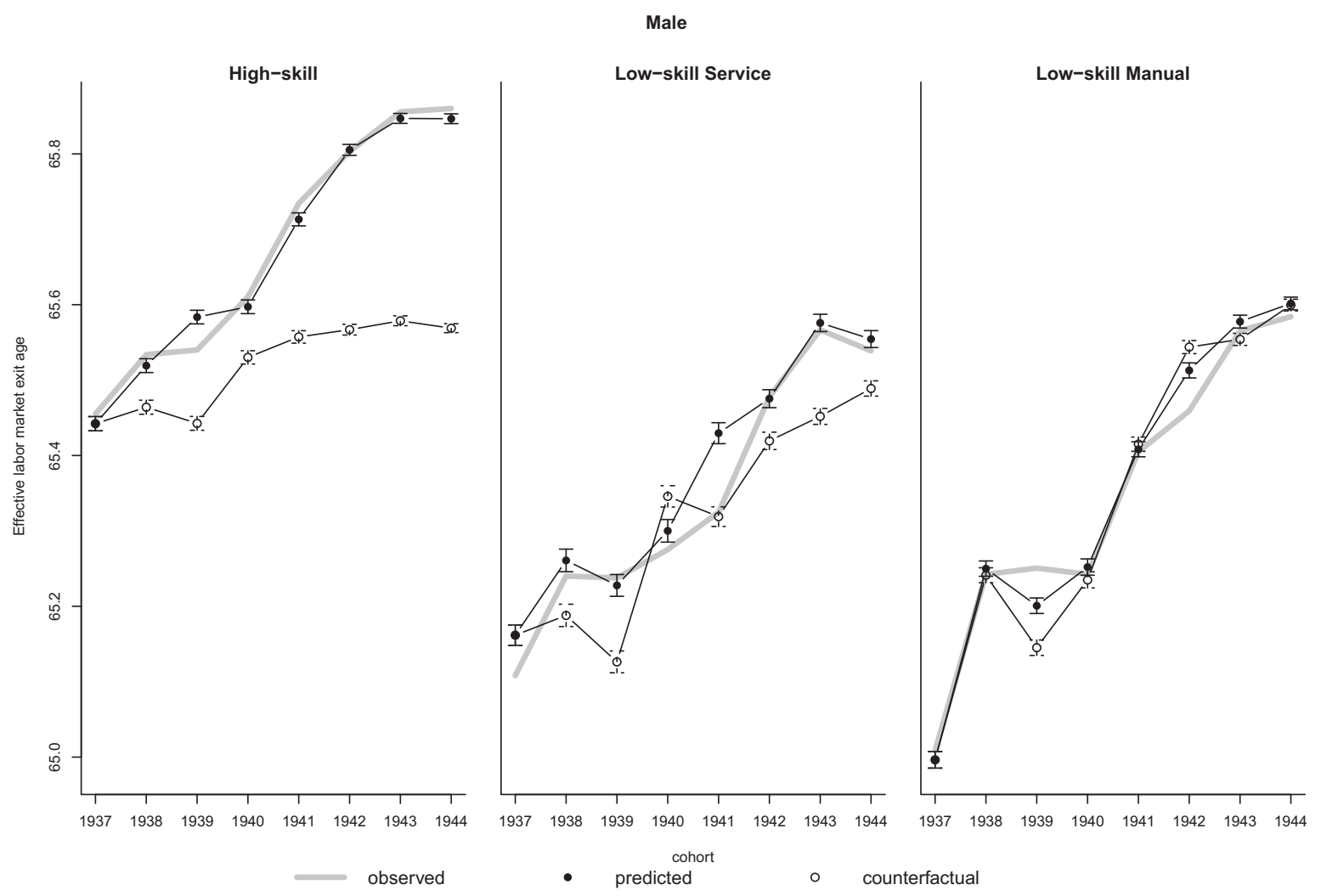

Female
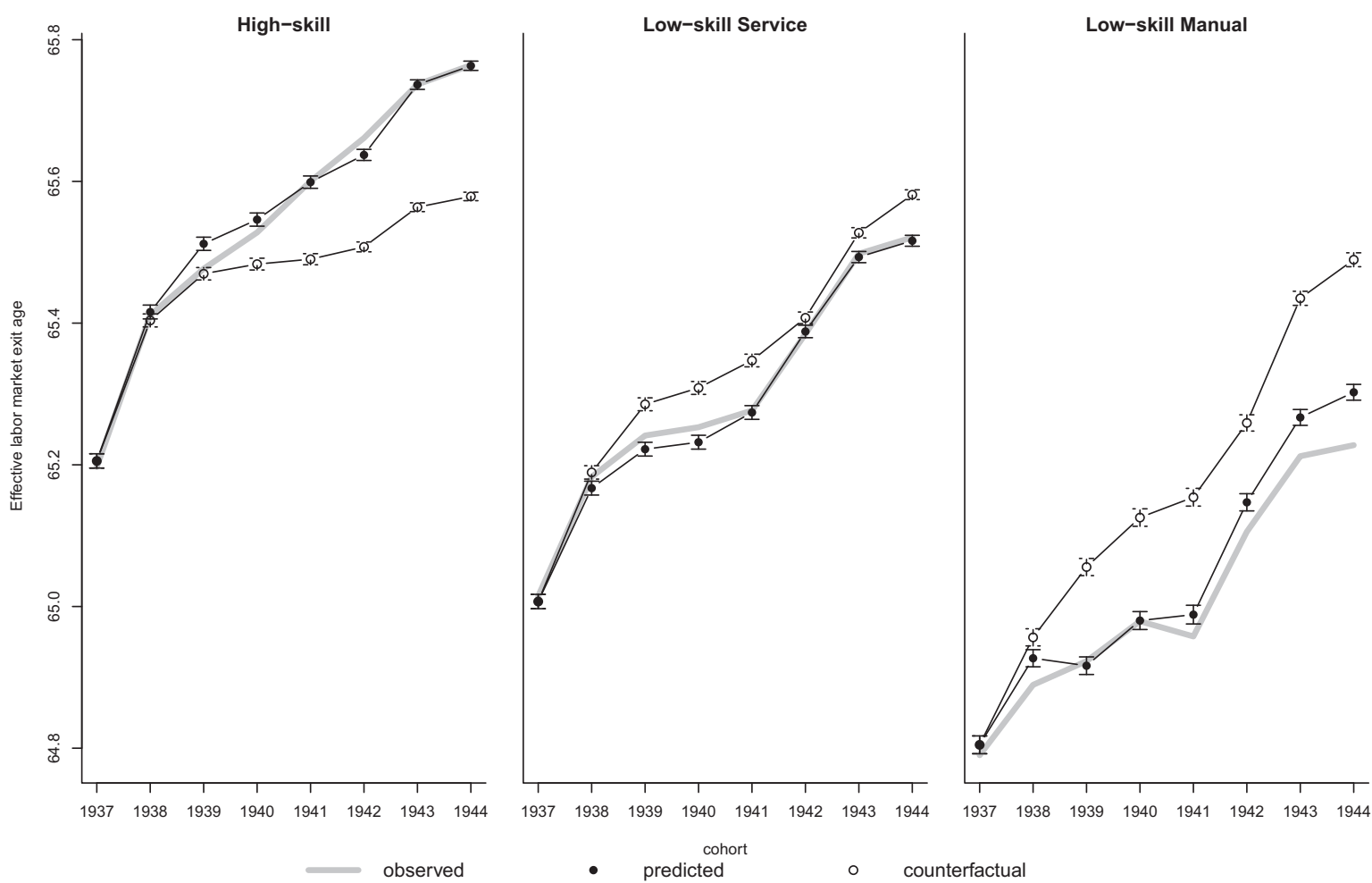

Fig. 10. Average retirement age by occupation.

occupation (52\%) and low-skill manual labor (39\%). ${ }^{3}$ As a result, the cohort pattern predicted by the model poorly match the observed

3 See Table 2. retirement age for this particular group. However, our model still captures the observed trend increases fairly well, which suggests that the phenomenon of working longer appears universal across different occupational groups. Fig. 11 presents the effects of NDC 


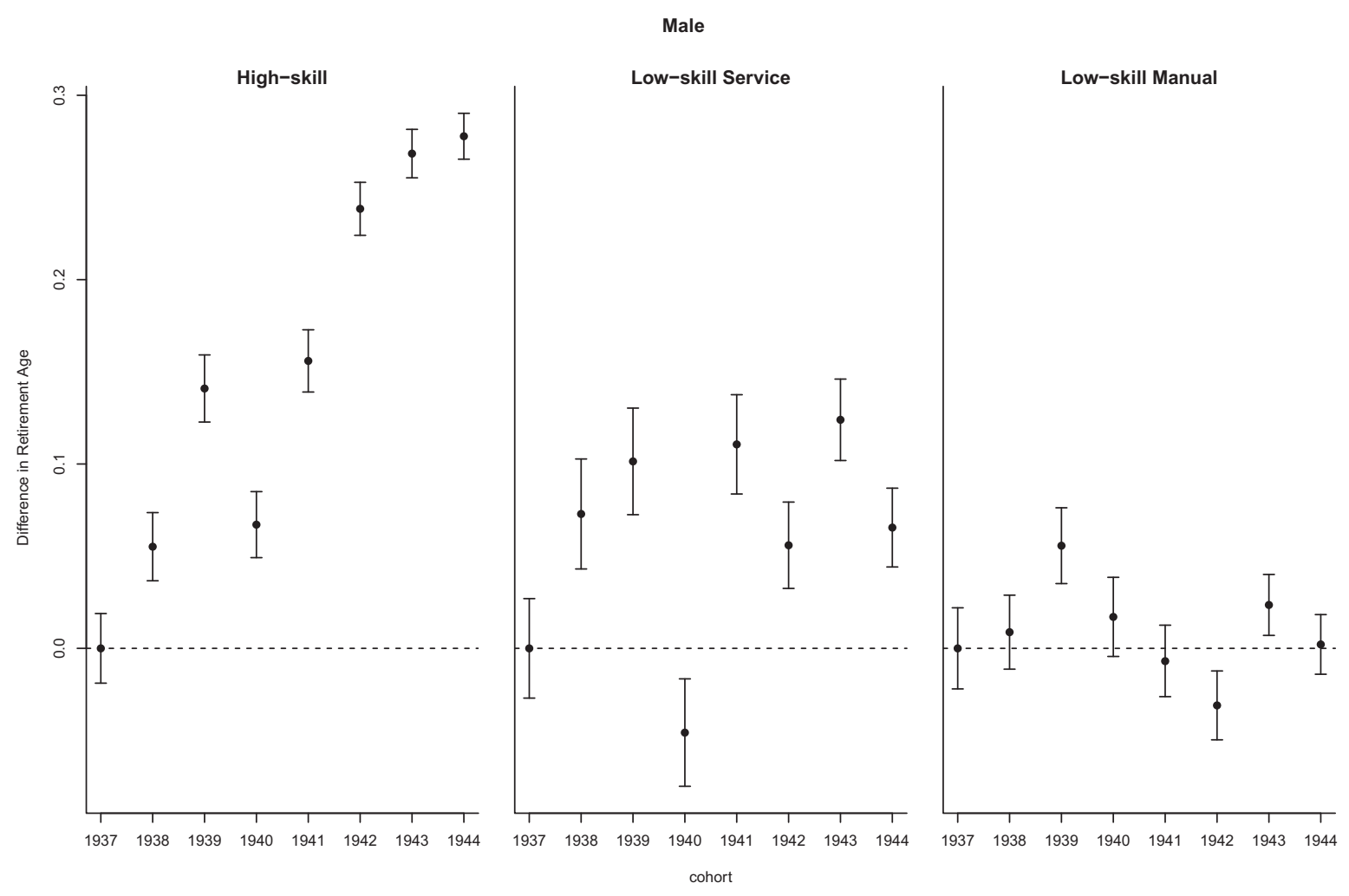

Female

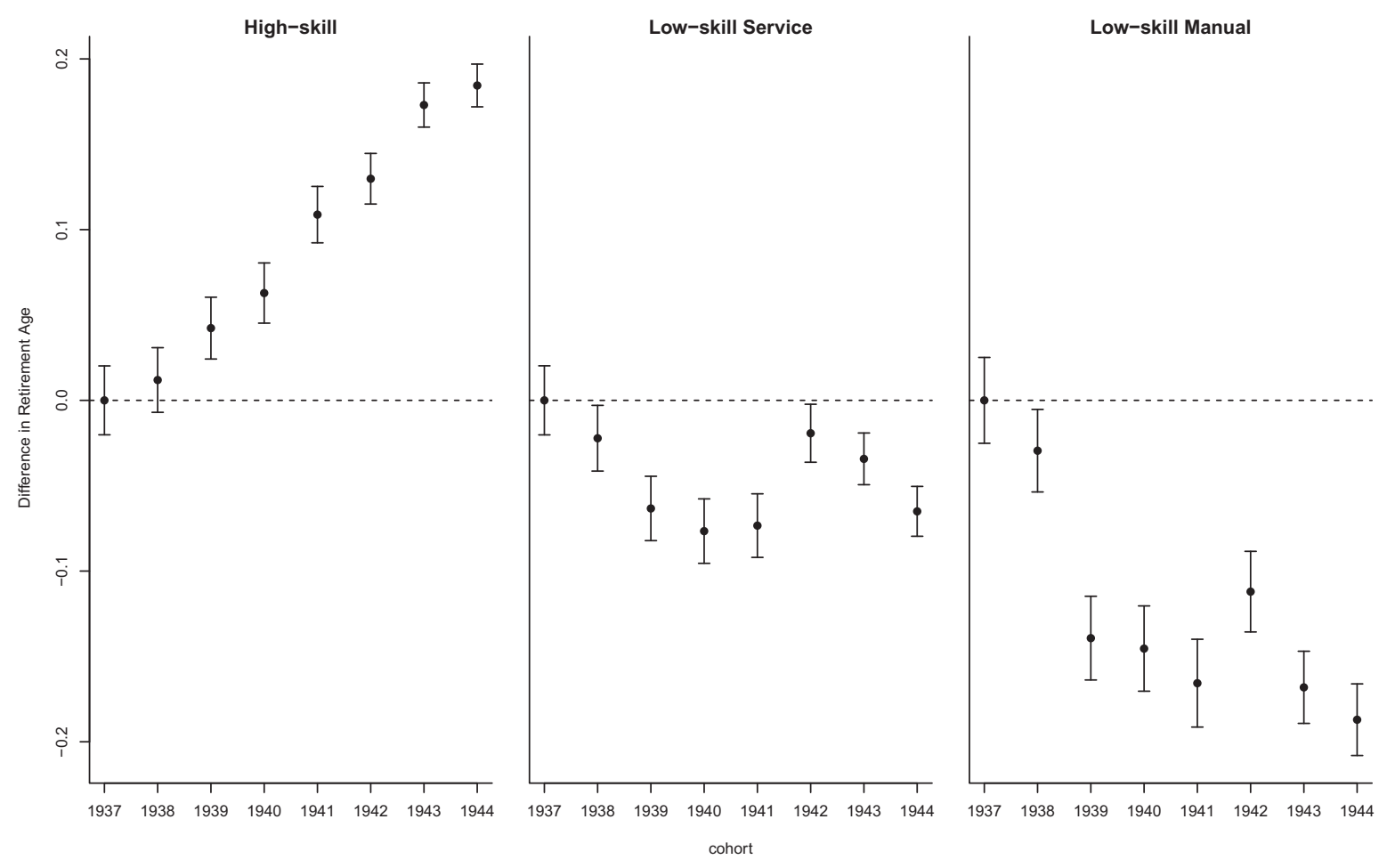

Fig. 11. Effect of NDC on average retirement age by occupation.

on retirement age by different occupational groups. The positive impacts are mainly concentrated among the high-skill labor, a pattern that nearly coincides with which for the highly educated shown in Fig. 9.
Our findings on the "New Labor Market" help us to identify the effects of pension policy amendments with greater precision for different groups, and suggest that NDC does not necessarily prolong working life for every one in the labor force. In fact, the results 
indicate a considerable socio-economic gradient of the labor supply effects of NDC.

The main reason for the different group responses to the reform is that, as discussed earlier, NDC reversed the redistribution (from low- to high-income earners) that originally existed in ATP. Hence, the reform, in fact, increased the benefits for those low-income earners who were commonly less educated and work in lowskilled jobs. The consequence of this increased benefit is that the pecuniary value and probability of retiring were elevated, and eventually the mean retirement age for these specific groups were lower than it otherwise would have been. On contrary, NDC result in benefit reduction for those highly educated and skilled labor (typically high income earners), which created strong incentives for them to work longer.

These different responses imply that the aggregate labor supply impact of phasing in the NDC pension scheme may depend on the composition of the old-aged labor force, namely how large is the share of older workers attained higher education and working as high-skill labor. A positive aggregate impact may be expected if the share of highly educated and skilled is large. And conversely, a small or even negative effect might not be unexpected if the majority of old-aged workforce having only attained primary education and engaged in low-skill jobs.

\section{Conclusion}

Sweden, together with Italy, Latvia, and Poland, are the first four countries in the world reformed their old-age pension system by phasing in the NDC scheme during the 1990s. One of the key purposes of NDC is to create financial incentives for working longer by linking worker's pension contribution more closely to retirement benefits than the traditional defined-benefit pay-as-you-go system. While pension reformers opt for NDC with the expectation that the average effective retirement age may increase, empirical evidence regarding whether the system has met such an expectation has been scarce. This is simply because the effects were too early to be examined previously, as generations who were effectively affected had not yet reached their pensionable age. Recently, some of the birth cohorts who are covered by the Swedish NDC system have reached their late 60s, and therefore provides the opportunity to address the question "do NDC pension scheme prolong working life?"

Our analysis is based on a large population database with rich individual-level information, the Swedish Inter-disciplinary Panel (SIP). The database covers the entire population residing in Sweden sometime between 1968 and 2011 with information on yearly income from all sources, as well as a broad set of socio-economic and demographic variables. The data shows that the average retirement age has been increasing across cohorts born between 1938 and 1944, regardless of gender, the level of educational attainment, and occupation. These trend increases seemingly suggest that NDC had a positive impact on retirement age, as these birth cohorts were effectively affected by the 1994 pension reform. However, comparing these upward trends with the counter-factual ones that eliminate the NDC driven cohort differences in pension income, we find that the overall effect is much greater for men, compared to women, a gender distinction has been uncovered in the previous literature. Additionally, the average retirement age in the absence of NDC would have been much lower among the highly educated and skilled older workers, but it would have been roughly the same for men, and even higher for women if they are with low level of human capital.

These findings imply that NDC did not necessarily prolong working life for all pensionable age workers, rather there is a gender and socio-economic gradient in terms of the labor supply response. This gradient further implies that the aggregate impact of a pension reform may be more complex than one might expect. The extent to which NDC may increase the average working life expectancy may be a function of the socio-economic characteristics of the old-aged labor force. If the labor force contains a large share of highly educated and skilled, a positive impact may be expected. However, if the majority of old-aged workers having attained only primary education and engaged in low-skill manual jobs, the aggregate impact might be small, or even adverse. These are the important aspects that pension reformers might want to consider when assessing the costs and benefits of phasing in the NDC scheme. Finally, the gender- and educational differences in responding to NDC highlights the importance of integrated ageing policy which is necessary to assist those who are more likely to face a stagnating income and limited job opportunities to adapt to the new policy environment.

We would like to conclude this paper by mentioning three caveats in our analysis. First, for non-retirees, we imputed their potential pension streams by using a regression-based forecasting equation. This approach is very different than which mostly adopted in the previous studies, whereby potential pensions are computed based on the simulated life-cycle earning profiles. It is impossible to justify which approach is more appropriate, as the potential pensions can never be compared with the actual values because they are unobservable. However, our approach does have an advantage, as it only requires to impute the unobserved information between age 60 and 67, whereas the alternative approach needs to simulate the labor income over the entire life-cycle. Moreover, as shown in Fig. 6, 8, and 10, the retirement model based on our imputed pensions generally match the observed patterns well, which indicates some reliability of our imputation approach.

The second limitations is that our analysis assumes that every one is retired at age 67 . This might largely underestimate the average retirement age, particularly for those later born cohorts. However, this assumption is motivated for two reasons. First, the 2001 Employment Act restricted workers to be fully engaged in labor activity over age 67 . And second, as shown in Table 1 , the older cohorts, particularly women, have a very small proportion remaining in the labor force at age 67 . This prevents our study from going beyond age 67 , as once the sample is stratified by education and occupation, the observed workers become too few, especially for the groups with low level of education and skills. Nonetheless, as we have already seen that younger cohorts are increasingly to work after age 67, labor market activity beyond 67 is certainly not negligible. For this, we will replicate a similar analysis once more younger cohorts having reached their 70 s and more updated information becoming available in the register data during the coming years.

The last noticeable caveat is that while this paper attributed one-third of men's increase in retirement age to the implementation of NDC, it left the variation in women's retirement age largely unexplained. In a recent study, Qi et al. (2016) showed that a quarter of the increase in labor supply among older women were due to a compositional change in the population, namely the female labor force became increasingly educated over time. Taking altogether, our current understanding of this trend increase in retirement age for both men and women is a combined forces of the pension reform and the increasingly educated female labor force. Whether the remained unexplained variation is due to changes in culture, norms, preferences, attitude, or labor market demand, these will be the subject for our future work.

\section{Acknowledgements}

We acknowledge financial support from the European Union's Seventh Framework Programme for research, technological devel- 
opment and demonstration under Grant Agreement No. 613247, Centre for Economic Demography at Lund University, Knut Wicksell Centre for Financial Studies at Lund University, and the Swedish Research Council (Vetenskapsrådet) via the Linnaeus Center for Social Policy and Family Dynamics in Europe (SPaDE), grant registration number 349-2007-8701. We are grateful to Anna Amilon, David Canning, Kerstin Enflo, Alexia Fürnkranz-Prskawetz, Hans Groth, Jan Lanke, Jeff Neilson, Peng Nie, Albert Park, Miguel Sanchez, Alfonso Sousa-Poza, and Feng Wang for their helpful comments.

\section{References}

Berkovec, J., Stern, S., 1991. Job exit behavior of older men. Econometrica 59 (1), 189-210.

Buchholz, S., Rinklake, A., Blossfeld, H.P., 2013. Reversing early retirement in germany a longitudinal analysis of the effects of recent pension reforms on the timing of the transition to retirement and on pension incomes. Compar. Population Stud. 38 (4)

Chan, S., Stevens, A.H., 2004. Do changes in pension incentives affect retirement? a longitudinal study of subjective retirement expectations. J. Public Econ. 88 (78), 1307-1333.

Glans, E., 2008. Retirement Patterns during the Swedish Pension Reform. Working Paper Series 2008:9, Uppsala University, Department of Economics.

Hagen, J., 2013. A History of the Swedish Pension System. Working Paper Series, Center for Fiscal Studies 2013:7, Uppsala University, Department of Economics.

Hakola, T., Uusitalo, R., 2005. Not so voluntary retirement decisions? evidence from a pension reform. J. Public Econ. 89 (1112), 2121-2136.

Holzmann, R., Palmer, E., 2006. Pension Reform: Issues and Prospects for NonFinancial Defined Contribution (NDC) Schemes. The World Bank, Washington, D.C..

Karlsson, H., Olsson, H., 2012. Medelpensioneringsalder och Uttradesalder 2011.

Karlström, A., Palme, M., Ingemar, S., 2008. The employment effect of stricter rules for eligibility for DI: evidence from a natural experiment in Sweden. J. Public Econ. 92, 2071-2082.
Komp, K., Tilburg, T., Groenou, M.B., 2010. Paid work between age 60 and 70 years in Europe: a matter of socio-economic status? Int. J. Ageing Later Life.

Konberg, B., Palmer, E., Sunden, A., 2006. The NDC reform in Sweden: the 1994 legislation to the present. In: Holzmann, R., Palmer, E. (Eds.), Pension Reform: Issues and Prospects for Non-financial Defined Contribution (NDC) Schemes. The World Bank, Washington D.C..

Laitner, J., Silverman, D., 2012. Consumption, retirement and social security: evaluating the efficiency of reform that encourages longer careers. J. Public Econ. 96 (78), 615-634.

Laun, T., Wallenius, J., 2015. A life cycle model of health and retirement: the case of Swedish pension reform. J. Public Econ. 127, 127-136.

Lumsdaine, R.L., Stock, J.H., Wise, D.A., 1992. Three models of retirement: computational complexity versus predictive validity. In: Wise, D.A. (Ed.), Topics in the Economics of Aging. University of Chicago Press.

Palmer, E., 2000. The Swedish Pension Reform Model: Framework and Issues. Discussion Papers No. 23086, The World Bank.

Qi, H., 2015. Real wage and labor supply in a quasi life-cycle framework: a macro compression by Swedish National Transfer Accounts (1985-2003). Vienna Yearbook Population Res. 2014 12, 83-114.

Qi, H., 2016. Live Longer, Work Longer? Evidence from Swedens Ageing Population. Ph.D. thesis, Lund University.

Qi, H., Bengtsson, T., Helgertz, J., 2016. Old-age employment in sweden: the reversing cohort trend. In: Qi, H. (Ed.), Live Longer, Work Longer? Evidence from Sweden's Ageing Population. Department of Economic History, Lund University, Lund, pp. 117-164. Number 75 in Lund Studies in Economic History, Chapter 4

Ruhm, C.J., 1996. Do pensions increase the labor supply of older men? J. Public Econ. 59 (2), 157-175.

Settergren, O., 2001. Two Thousand Five Hundred Words on the Swedish Pension Reform. Working Papers No. 2001:1, The National Social Insurance Board.

Staubli, S., Zweimuller, J., 2013. Does raising the early retirement age increase employment of older workers? J. Public Econ. 108, 17-32.

Stock, J.H., Wise, D.A., 1990. Pensions, the option value of work, and retirement Econometrica 58 (5), 1151-1180.

Sunden, A., 2006. How much do people need to know about their pensions and what do they know? In: Holzmann, R., Palmer, E. (Eds.), Pension Reform: Issues and Prospects for Non-financial Defined Contribution (NDC) Schemes. The World Bank, Washington D.C..

Vogler-Ludwig, K., Dull, N., 2008. Analysis of the Average Exit Age from the Labour Force. Report, European Commission. 